\title{
Working memory performance is tied to stimulus complexity
}

Roland Pusch ${ }^{1 * \$}$, Julian Packheiser ${ }^{1 \$}$, Amir Hossein Azizi ${ }^{2}$, Celil Semih Sevincik ${ }^{1}$, Jonas Rose ${ }^{3}$, Sen Cheng $^{4}$, Maik C. Stüttgen ${ }^{5}$, and Onur Güntürkün ${ }^{1}$

${ }^{1}$ Department of Biopsychology, Faculty of Psychology, Ruhr University Bochum, Universitätsstraße 150, D-44780 Bochum, Germany

${ }^{2}$ Department of Systems Biology, Agricultural Biotechnology Research Institute of Iran (ABRII), Karaj, Iran.

${ }^{3}$ Neural Basis of Learning, Faculty of Psychology, Ruhr University Bochum, Universitätsstraße 150, D44780 Bochum, Germany

${ }^{4}$ Institute for Neural Computation, Ruhr University Bochum, Universitätsstraße 150, D-44780 Bochum, Germany

${ }^{5}$ Institute of Pathophysiology, University Medical Center of the Johannes Gutenberg University, Duesbergweg 6, D-55128 Mainz, Germany

* Correspondence: roland.pusch@rub.de

\$ These authors contributed equally 


\section{Summary}

Working memory is the cognitive capability to maintain and process information over short periods. Recent behavioral and computational studies have shown that increased visual information of the presented stimulus material is associated with enhanced working memory performance. However, the underlying neural correlates of this association are unknown. To identify how stimuli of different visual information levels affect working memory performance, we conducted behavioral experiments and single unit recordings in the avian analog of the prefrontal cortex, the nidopallium caudolaterale (NCL). On the behavioral level, we confirmed that feature-rich complex stimuli demonstrated higher working memory performance compared to feature-poor simple stimuli. This difference was reflected by distinct neural coding patterns at the single unit level. For complex stimuli, we found a highly multiplexed neuronal code. During the sample presentation, NCL neurons initially reflected both visual and value-related features of the presented stimuli that switched to a representation of the upcoming choice during a delay period. When processing simple stimuli, NCL neurons did not multiplex and represented the upcoming choice already during stimulus presentation and throughout the delay period. It is conceivable that the maintenance of the upcoming choice in working memory was prolonged for simple stimuli due to the early choice representation. This possibly resulted in increased decay of the working memory trace ultimately leading to a decrease in performance. In conclusion, we found that increases in stimulus complexity are associated with increased neuronal multiplexing of the working memory representation. This could possibly allow for a facilitated read-out of the neural code resulting in further enhancements of working memory performance.

Keywords: avian cognition, pigeons, decision-making, multiplexing, stimulus information 


\section{Introduction}

Working memory, the ability to maintain and process information in the absence of sensory stimuli, is crucial for many cognitive functions like abstract reasoning, problem solving, goal-directed behavior, decision making and cognitive control (Hassin et al., 2009). This important role in cognition is further illustrated by the fact that the capacity of working memory is often taken as proxy for overall cognitive capacity (Conway et al., 2003; D’Esposito and Postle, 2015). A large body of research has demonstrated that especially the prefrontal cortex (PFC) is involved in the active maintenance of sensory input (Funahashi, 2015; Fuster and Alexander, 1971; Lundqvist et al., 2016; for review, see Funahashi, 2017 and Lara and Wallis, 2015). Most studies investigating the neural basis of working memory focused on the specific effects of increased working memory load (Buschman et al., 2011; Tang et al. 2019; for review, see Constantinidis and Klingberg, 2016), influence of reward associations (Kennerley and Wallis, 2009; Krawczyk et al., 2007) or the role of attention (Buschman and Miller, 2007; Panichello and Buschman, 2021). Surprisingly, the stimulus that is used in a working memory paradigm has received comparatively little attention in neuroscience.

In a behavioral study, Gegenfurtner and Rieger (2000) investigated the impact of color on encoding and retrieval processes. They found that recognition and recall of colored stimuli was faster and more successful than recognition of black and white images. Bae et al. $(2014,2015)$ investigated the precision of working memory in delayed estimation tasks using plain colors as stimuli. In these experiments, a target color had to be remembered throughout a retention interval. Subsequently, the target color had to be recalled and estimated on a continuous color wheel. The deviation of the chosen color from the presented stimulus indicated the memory precision for a specific hue. Importantly, the authors found an inhomogeneous response distribution where specific colors were maintained more precisely than others, even when remembering a single stimulus. These results were later replicated in humans and monkeys and modelled as drift towards adaptive attractors. According to these models, neural representations in working memory are more resistant to noise when they are stored in stable 
bioRxiv preprint doi: https://doi.org/10.1101/2021.09.10.459776; this version posted September 11, 2021. The copyright holder for this preprint (which was not certified by peer review) is the author/funder, who has granted bioRxiv a license to display the preprint in perpetuity. It is made available under aCC-BY-NC 4.0 International license.

states associated with for example primary colors (Panichello et al., 2019). Similar findings were made by Pratte et al. (2017) using the orientations of gratings as stimuli. As for color vision, the authors found an inhomogeneous distribution for the recall of orientations with a superior memory performance for cardinal orientations. The abovementioned empirical and modeling work indicates the influence of stimulus material on memory performance, a notion that is further illustrated by the interaction between working memory and perception (Kang and Spitzer, 2021).

While these recent behavioral and modeling studies have demonstrated that the stimulus material indeed affects working memory, the possible underlying neural computations remain elusive. To provide insights into these processes, we investigated the impact of stimulus complexity on working memory performance in three behavioral experiments. Specifically, we aimed to identify whether differing levels of stimulus complexity (high or low spatial and color information) affect working memory performance. We chose pigeons as a model organism for the present study due to their excellent color vision (Güntürkün, 2000), their ability to quickly learn and memorize visual stimuli (Güntürkün et al., 2014), and to categorize pictures on par with monkeys (Wright and Elmore, 2016). Further, all investigated functional parameters of working memory have been suggested to be comparable between birds and mammals (e.g., Wright and Elmore, 2016; Balakhonov and Rose, 2017). Across all behavioral experiments, we consistently found higher working memory performance rates for high compared to low stimulus complexity. In a final experiment, we complemented these behavioral findings with single-unit recordings from the nidopallium caudolaterale (NCL). This structure has been suggested to be the avian analogue to the mammalian PFC based on neurochemical results (e.g. Karakuyu, 2007), connectivity patterns (e.g. Kröner and Güntürkün, 1999) and its role in executive functions (e.g. Veit et al., 2014), especially working memory (Diekamp et al., 2002; Moll and Nieder, 2015). Here, we found a systemic difference in the neural representation of choice timing and dimensionality between the two stimulus classes. 


\section{Results}

\section{Behavior}

In three behavioral experiments, we investigated the effect of stimulus complexity on working memory by comparing performance accuracy with and without a delay in a paired association task. All trials in the experiments followed the same structure (see Figure 1A and STAR methods for details): After a center peck to initialize the trial, a Sample phase of $1 \mathrm{~s}$ duration began, during which a single stimulus was presented on the center response-key. In the non-delayed condition, the choice period started after another peck onto a confirmation key following the sample phase. In the delayed condition, a $3 \mathrm{~s}$ delay phase was imposed between the sample and the choice phase. During the choice phase, the animals had up to $3 \mathrm{~s}$ to make a choice either to peck on the left or on the right response key (counterbalanced across animals). A correct choice resulted in a $2 \mathrm{~s}$ food presentation whereas an incorrect choice resulted in a mild punishment with a $2 \mathrm{~s}$ lights out condition in the experimental chamber. In each experiment, eight different images were presented as stimuli. Four 'complex' stimuli consisted of multiple colors as well as spatial features and four 'simple' stimuli consisted of a single grayscale value of different luminance (Figure 1B, left panel). We will use the terminology complex vs. simple throughout the manuscript to refer to the two stimulus classes (for more detail on stimulus characterization, refer to the STAR methods).

A

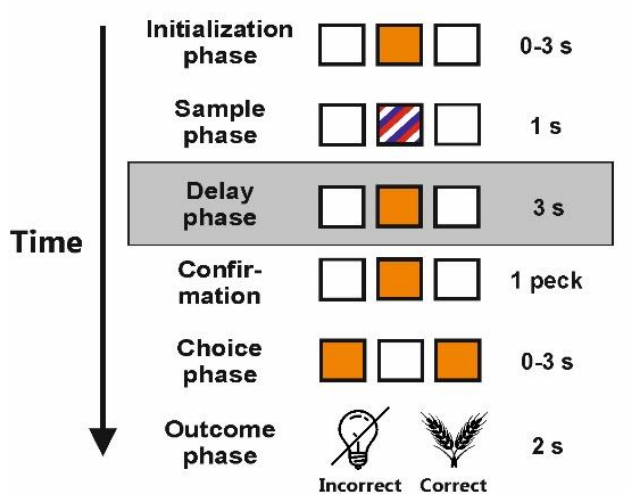

B

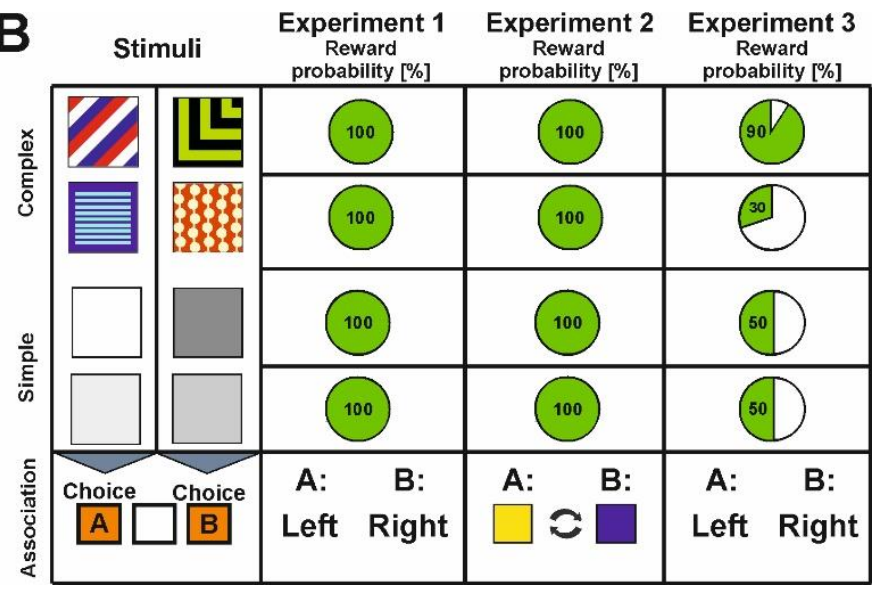

Figure 1. Behavioral paradigm, stimuli and experimental conditions. A) Depiction of the paired association task used during each experiment. The boxes represent the pecking keys in the operant chamber and their illumination for each phase. On the 
bioRxiv preprint doi: https://doi.org/10.1101/2021.09.10.459776; this version posted September 11, 2021. The copyright holder for this preprint (which was not certified by peer review) is the author/funder, who has granted bioRxiv a license to display the preprint in perpetuity. It is made available under aCC-BY-NC 4.0 International license.

right, the duration of each phase is stated. The gray frame around the Delay phase indicates that it was only present in the delayed condition. B) In the left panel, the stimuli used in our paradigm are depicted. In the panels to the right, reward probabilities for the stimuli across the experiments are presented. In experiment 1 and 2, all stimuli were followed by food for every correct choice. In experiment 3 and during the physiological recordings, correct responses were rewarded with different probabilities. The bottom row demonstrates what choices had to be made in each experiment. Experiment 1 and 3 required spatially fixed choices associated with each stimulus (choice $A=$ left choice, choice $B=$ right choice). The stimuluschoice associations were counterbalanced across stimuli. In Experiment 2, the stimuli were associated with a specific target color (choice $A=$ yellow, choice $B=$ blue) that varied in its spatial location from trial to trial during the experimental session.

\section{Experiment 1}

The first experiment had two aims: First, we wanted to establish if the animals could discriminate equally well between complex and simple stimuli. For this purpose, we analyzed the non-delayed condition of our task. Our second aim was to explore the effects of stimulus-complexity on working memory performance. For this purpose, we compared the results from the non-delayed with the delayed condition of our task. In experiment 1 , the animals associated each stimulus with either the left or the right response key. All stimuli were rewarded in $100 \%$ of the cases if the correct choice was made (Figure 1B, Experiment 1).

89 behavioral sessions from 12 animals were analyzed. To identify whether performance was affected by stimulus complexity, we compared the number of correct responses between complex and simple stimuli in the non-delayed condition using a linear mixed model. We found no significant difference between the performance for complex stimuli (93.6\% correct responses) and the performance for simple stimuli $(92.5 \%$ correct responses, $\beta=-0.01,95 \% \mathrm{Cl}=[-0.03-0.003]$, standard error $(\mathrm{SE})=0.01$, $t=1.46, p=0.148, d=0.29,95 \% \mathrm{Cl}=[-0.11-0.69])$. This indicates that complex and simple stimuli could be discriminated equally well if no working memory component was present in the task (Figure 2A).

Next, we compared the number of correct responses for both stimulus classes in the delayed and nondelayed condition to investigate how stimulus complexity affects maintenance. We found that the introduction of the delay had differential effects on the two stimulus classes (interaction class*delay: $\beta=-0.07,95 \% \mathrm{Cl}=[-0.09--0.04], \mathrm{SE}=0.01, p<0.001$, for random effects residuals, see SI Table 1$).$ For complex stimuli, there was moderate evidence that correct responses decreased following the introduction of the delay (no delay $=93.5 \%$ correct responses; delay $=91.0 \%$ correct responses, $t=$ 
$2.62, p=0.009, d=0.61,95 \% \mathrm{Cl}=[0.15-1.08])$. For simple stimuli, there was very strong evidence that the performance was significantly reduced due to the imposed delay (no delay $=92.4 \%$ correct responses; delay $=83.1 \%$ correct responses; $t=9.80, p<0.001, d=2.29,95 \% \mathrm{Cl}=[1.77-2.81])$. Results for the individual stimuli are presented in SI Figure 1. Of important note for a later experiment is that there was moderate evidence of a performance difference between simple stimuli that were separated by low and high contrast increments. Low contrast simple stimuli received less correct responses compared to stimuli separated by higher contrast differences (Low contrast $=90.8 \%$ correct responses; high contrast $=86.5 \%$ correct responses, $t=4.71, p<0.001, d=0.71,95 \% \mathrm{Cl}=[0.41-$ 1.01]). However, the performance decline for both high and low contrast stimuli was uniform across the delay indicating that this effect was likely working memory independent.

\section{Experiment 2}

In the first experiment, we found that complex stimuli could be maintained more accurately over time compared to simple stimuli. However, the task in experiment 1 demanded a spatially fixed choice to the left or to the right depending on the stimulus identity. To control for spatial memory effects or motor preparation strategies, e.g. preemptively locating oneself closer to the respective choice target, we repeated the experiment, but replaced the spatially fixed response associations with randomly presented color associations (choice $\mathrm{A}=$ blue, choice $\mathrm{B}=$ yellow, counterbalanced across animals; Figure $1 \mathrm{~B}$, Experiment 2). Thus, the target location for the upcoming choice could no longer be predicted by the animals.

36 behavioral sessions from eight animals were analyzed for experiment 2. As in experiment 1 , we found differential effects of the delay depending on the stimulus class (interaction of class*delay: $\beta=$ $-0.08,95 \% \mathrm{Cl}=[-0.12--0.04], \mathrm{SE}=0.02, p<0.001$, Figure 2B, for random effects residuals, see SI Table 1). There was moderate evidence that the delay had any effect on the performance for complex stimuli (no delay $=93.6 \%$ correct responses, delay $=90.8 \%$ correct responses, $t=1.89, p=0.063, d=0.63,95$ $\% \mathrm{Cl}=[-0.04-1.31])$. For simple stimuli, there was very strong evidence that the introduction of the 
bioRxiv preprint doi: https://doi org/10.1101/2021.09.10.459776; this version posted September $11,2021$. The copyright holder for this preprint (which was not certified by peer review) is the author/funder, who has granted bioRxiv a license to display the preprint in perpetuity. It is made available under aCC-BY-NC 4.0 International license.

delay decreased performance rates (no delay $=93.2 \%$ correct responses, delay $=82.1 \%$ correct responses, $t=7.46, p<0.001, d=2.50,95 \% \mathrm{Cl}=[1.71-1.08])$. These findings strongly resemble the findings from the first experiment and show that complex stimuli were maintained more accurately than simple stimuli. Importantly, this effect could not be explained by spatial memory effects or motor preparation strategies. Results for the individual stimuli are presented in SI Figure 2. Similar to experiment 1, we found moderate evidence that there was a difference between high and low contrast simple stimuli $(t=2.59, p=0.063, d=0.59,95 \% \mathrm{Cl}=[0.13-1.04])$, but the performance decline was uniform across both.
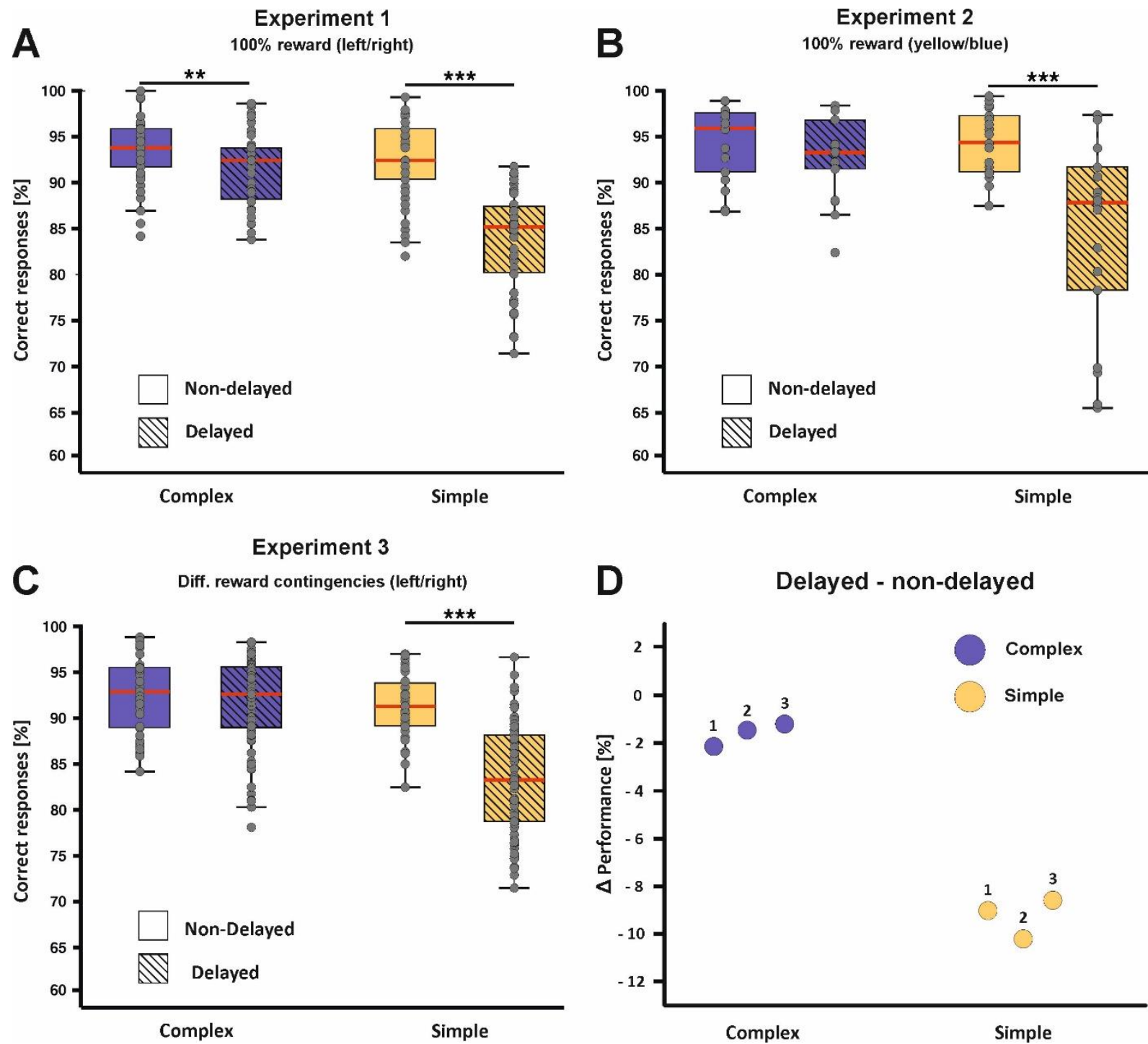

Figure 2. Behavioral performance for the experiments 1-3. A) Experiment 1: In the non-delayed condition, no performance difference was found between complex (blue) and simple stimuli (yellow) indicating that both stimulus classes could be successfully associated with their corresponding choice if no working memory component was present. Following the introduction of the delay, a much larger performance drop was observed for simple compared to complex stimuli. Dots represent individual sessions in the respective experimental condition. B) Experiment 2: Dissociating the upcoming choice 
bioRxiv preprint doi: https://doi.org/10.1101/2021.09.10.459776; this version posted September 11, 2021. The copyright holder for this preprint (which was not certified by peer review) is the author/funder, who has granted bioRxiv a license to display the preprint in perpetuity. It is made available under aCC-BY-NC 4.0 International license.

from a fixed spatial location had no effects on the result pattern that was observed in experiment 1. C) Experiment 3: As in experiment 1 and 2, performance decreases following the introduction of the delay were much more pronounced for simple compared to complex stimuli. D) Percentage difference $(\Delta)$ of the performance between the delayed vs. the non-delayed condition for complex and simple stimuli. The numbers next to the circles indicate the performance difference in the specific experiment. $* * p<0.01, * * * p<0.001$. Error bars represent the $95 \%$ confidence interval.

\section{Experiment 3}

In experiment 1 (and tentatively in experiment 2), we found that simple stimuli separated by low contrast differences received less correct responses compared to simple stimuli separated by higher contrast differences. Thus, overall animals received less food when confronted with low compared to high contrast stimuli resulting in different reward net outcomes. To control for differing outcomes within the simple stimulus class, we modulated the reward contingencies associated with the complex stimuli as well in experiment 3. Thus, one pair of complex stimuli was subsequently associated with a high reward probability (90\%), while the other pair of complex stimuli was associated with a low probability (30\%, counterbalanced across animals). The clear divergence in reward probability was chosen to achieve a pronounced difference in the overall net outcome among the complex stimuli. Reward probabilities for the simple stimuli were kept at identical rates (50 \%) to compare the effects of net outcome difference via reward probability or discrimination difficulty (Figure 1B, Experiment 3).

104 behavioral sessions from 17 animals were analyzed for experiment 3. Reiterating the effects in experiment 1 and 2, we found a differential effect of the introduction of the delay across the two stimulus classes (interaction of class*delay: $\beta=-0.07,95 \% \mathrm{Cl}=[-0.10--0.04], \mathrm{SE}=0.01, p<0.001$, Figure 2C, for random effects residuals, see SI Table 1). Even though we modulated reward probabilities across the complex stimuli, there was no evidence that the delay had any effect on maintenance (no delay: $92.2 \%$ correct responses, delay $=92.8 \%$ correct responses, $t=0.39, p=0.700$, $d=0.11,95 \% \mathrm{Cl}=[-0.46-0.67])$ indicating that very high or very low reward rates did not affect working memory. For simple stimuli, there was very strong evidence that the delay affected performance (no delay $=91.0 \%$ correct responses; delay $=84.2 \%$ correct responses, $t=4.99, p<0.001$, $d=1.41,95 \% \mathrm{Cl}=[0.82-1.99])$. Results for the individual stimuli are presented in SI Figure 3 . In agreement with the behavioral results based on different net outcomes for the simple stimuli, we 
bioRxiv preprint doi: https://doi. org/10.1101/2021.09.10.459776; this version posted September 11, 2021. The copyright holder for this preprint (which was not certified by peer review) is the author/funder, who has granted bioRxiv a license to display the preprint in perpetuity. It is made available under aCC-BY-NC 4.0 International license.

found attenuated performance levels when stimuli were associated with low reward probabilities compared to stimuli associated with high reward probabilities when no delay was imposed. Here, high reward stimuli received more correct responses compared to low reward stimuli (high reward $=96.0$ $\%$ correct responses; low reward $=90.9 \%$ correct responses, $t=11.37, p<0.001, d=1.58,95 \% \mathrm{Cl}=$ $[1.28-1.87])$. This suggests that reward probabilities affected the general ability to associate stimuli with the adequate choice.

In conclusion, we consistently showed in three behavioral experiments that stimulus complexity had a strong impact on working memory performance. If stimuli were rich in visual information, the introduction of a memory-delay only had small, if any effects on maintenance. If simple stimuli, lacking spatial and color information, were presented, performance was significantly diminished following a memory-delay (see Figure 2D for an overview across all three experiments).

Since we used individual sessions from the included animals in all experiments, we repeated the analysis by averaging the data across all sessions for each animal and then only included one data point per individual to exclude that the effects were driven by single animals. In this analysis, we found an interaction between stimulus class and delay $(\beta=-0.05,95 \% \mathrm{Cl}=[-0.08--0.02], \mathrm{SE}=0.02, p=0.003$, for random effects residuals, see SI Table 1). There was moderate evidence that the delay had an effect on the performance for complex stimuli (no delay $=93.0 \%$ correct responses, delay $=90.8 \%$ correct responses, $t=1.79, p=0.078, d=0.58,95 \% \mathrm{Cl}=[-0.07-1.23])$. For simple stimuli, there was very strong evidence that the introduction of the delay decreased performance rates (no delay $=91.1 \%$ correct responses, delay $=83.9 \%$ correct responses, $t=6.01, p<0.001, d=1.94,95 \% \mathrm{Cl}=[1.22-$ 2.65], see SI Figure 4).

\section{Electrophysiology}

In a next step, we aimed to understand in how far differences in the neural representation of complex and simple stimuli can account for the differences in working memory performance that we observed in the behavioral experiments. To this end, we recorded single neuron activity in the NCL while the 
animals performed the delayed condition of experiment 3 as this condition comprised all relevant manipulations, i.e. working memory for stimuli of different complexity, as well as the manipulation of value.

\section{Neural recordings}

104 neurons from 34 behavioral sessions of three pigeons were recorded from the NCL (for histological electrode track reconstruction see SI Figure 5). Performance rates were highly comparable between the recording sessions and the purely behavioral sessions from the delayed condition of experiment 3 (see SI Figure 6).

At first, we were interested in the neural representation of task parameters. Particularly, we investigated if there were systematic differences between the two stimulus classes during working memory. Therefore, we analyzed trials with complex and simple stimuli independently using a sliding window ANOVA ( $250 \mathrm{~ms}$ bin size) with the factors "value" (levels high vs. low reward probability for complex stimuli or high vs. low contrast for simple stimuli) and "response" (two levels: left or right). For each factor, we computed the effect size $\eta_{p}{ }^{2}$ in each given bin of the trial (see Fig $3 \mathrm{~A}$ for illustration of these factors). We classified each neuron into four categories based on the resulting effect sizes (see STAR methods section for details):

1. Stimulus-related activity: One specific stimulus was encoded $\left(\eta_{p}{ }^{2}>0.03\right.$ in two consecutive bins for the factors "value", "response" and their "interaction" simultaneously (Rainer et al., 1999).

2. Value-related activity: A difference between high and low reward or high and low contrast (factor "value" $\eta_{p}^{2}>0.03$ in two consecutive bins).

3. Integrative representations: The interaction between the factors "value" and "response" $\left(\eta_{p}^{2}\right.$ $>0.03$ in two consecutive bins). 
bioRxiv preprint doi: https:/doi org/10.1101/2021.0910.459776; this version posted September 11,2021 . The copyright holder for this preprint (which was not certified by peer review) is the author/funder, who has granted bioRxiv a license to display the preprint in perpetuity. It is made available under aCC-BY-NC 4.0 International license.

4. Choice-related activity: A difference between left and right choices (factor "response" $\eta_{p}{ }^{2}>$ 0.03 in two consecutive bins)

Table 1 gives an overview of the cell categories across the experimental phases. To provide a comparison of activity patterns during the sample phase $(1 \mathrm{~s})$ and the delay phase $(3 \mathrm{~s})$, we divided the delay phase into three time windows of $1 \mathrm{~s}$ duration. To identify if the number of classified cells were above what was to be expected by chance, we randomly permutated spike counts to determine how often neurons were classified into each category based on chance alone (see STAR methods for detail, SI Table 2 for results). Finally, we used Fisher's exact test to identify whether the classification result was significantly different from the chance-based prediction. We used a Bonferroni corrected threshold of $p<0.0025$ due to the 20 individual comparisons performed for each stimulus class. Note that individual neurons could potentially be classified into multiple categories, as the categories were not mutually exclusive.

During the sample phase, a number of neurons displayed stimulus- $(19.23 \%)$ and value-related (12.5\%) activity or integrative representations (12.5\%) for complex stimuli, which was significantly different from chance (Table 1). The number of choice coding neurons was not significant from chance (7.69 \%). The presentation of simple stimuli during the sample phase resulted in a different activity pattern: The NCL population did not demonstrate significant numbers of neurons representing stimulus- $(0.96 \%)$ nor value-related $(0 \%)$ activity nor integrative coding $(0.96 \%)$. However, the number of neurons displaying choice-related activity were above chance (20.19\%).

In the first second of the delay, we found a significant fraction of integrative representations in NCL neurons (14.42 \%) for complex stimuli. Moreover, during all three seconds of the delay, a significant fraction of neurons represented the upcoming choice $\left(1^{\text {st }}\right.$ second: $32.69 \% ; 2^{\text {nd }}$ second: $23.08 \% ; 3^{\text {rd }}$ second: $23.08 \%)$. For simple stimuli, only choice-related activity was displayed throughout the delay period ( $1^{\text {st }}$ second: $34.62 \% ; 2^{\text {nd }}$ second: $27.88 \% ; 3^{\text {rd }}$ second: $27.88 \%$ ).

Table 1. Distribution of active cells per category (stimulus, value, integrative and choice representations) across the sample and delay phase for both the complex and simple stimuli. The color code indicates if the number of observed neurons is 
bioRxiv preprint doi: https://doi.org/101101/2021.0910 459776; this version posted September 11 2021. The copyright holder for this preprint (which was not certified by peer review) is the author/funder, who has granted bioRxiv a license to display the preprint in perpetuity. It is made available under aCC-BY-NC 4.0 International license.

higher than expected by chance (Fisher's exact test). Please note that the categories are not mutually exclusive as one neuron can for example exhibit both stimulus coding as well as value coding during the sample phase. For that reason, the cell total is not necessarily equal to the sum of all active neurons. P-value thresholds are Bonferroni corrected.

\begin{tabular}{|c|c|c|c|c|c|c|c|c|c|c|}
\hline \multirow{2}{*}{\begin{tabular}{|c|} 
Stimulus Set \\
$\begin{array}{c}\text { Phase Activity } \\
\text { in Trial }\end{array}$ \\
\end{tabular}} & \multicolumn{5}{|c|}{ Complex Stimuli } & \multicolumn{5}{|c|}{ Simple Stimuli } \\
\hline & Stimulus & Value & Integration & Choice & $\begin{array}{l}\text { Cell } \\
\text { Total }\end{array}$ & Stimulus & Value & Integration & Choice & $\begin{array}{l}\text { Cell } \\
\text { Total }\end{array}$ \\
\hline Sample Phase & $20(19.23 \%)$ & $13(12.5 \%)$ & $13(12.5 \%)$ & $8(7.69 \%)$ & $48(46.15 \%)$ & $1(0.96 \%)$ & $0(0 \%)$ & $1(0.96 \%)$ & $21(20.19 \%)$ & $23(22.12 \%)$ \\
\hline Delay $1^{\prime \prime}$ second & $5(4.81 \%)$ & $10(9.62 \%)$ & $15(14.42 \%)$ & $34(32.69 \%)$ & $39(37.5 \%)$ & $0(0 \%)$ & $0(0 \%)$ & $1(0.96 \%)$ & $36(34.62 \%)$ & $37(35.58 \%)$ \\
\hline Delay $2^{\mathrm{mid}}$ second & $2(1.92 \%)$ & $4(3.85 \%)$ & $5(4.81 \%)$ & $24(23.08 \%)$ & $33(31.73 \%)$ & $0(0 \%)$ & $3(2.88 \%)$ & $3(2.88 \%)$ & $29(27.88 \%)$ & $34(32.69 \%)$ \\
\hline Delay $3^{\text {rd }}$ second & $2(1.92 \%)$ & $3(2.88 \%)$ & $1(0.96 \%)$ & $24(23.08 \%)$ & $30(28.85 \%)$ & $1(0.96 \%)$ & $4(3.85 \%)$ & $2(1.92 \%)$ & $29(27.88 \%)$ & $33(31.73 \%)$ \\
\hline
\end{tabular}

$$
p>0.05
$$$$
p<0.05
$$$$
\mathrm{p}<0.01
$$

$p<0.001$

We further quantified the difference in effect size between stimulus classes during the sample and delay phase. This was done to evaluate differences of activity patterns between complex and simple stimuli trials and was again performed separately for the different task periods, i.e. the sample phase, $1^{\text {st }}$ second of the delay, $2^{\text {nd }}$ second of the delay and $3^{\text {rd }}$ second of the delay.

\section{Stimulus-related activity}

The first aspect we investigated was stimulus-related activity, i.e. whenever a neuron represented one stimulus in particular. An example neuron of this kind can be found in Figure $3 B$ (raster plot) and $3 C$ (spike density function or SDF). This neuron was selectively activated during the presentation of one particular complex stimulus exclusively during the sample phase (stimulus effect size is highlighted in yellow).

The results for stimulus-related activity of each recorded neuron are presented in Figure 3D (left: complex stimuli, right: simple stimuli). Stimulus-related activity was most prevalent during the sample phase and could almost exclusively be found for complex stimuli. We then compared the average effect of stimulus-related activity between both stimulus classes during the sample phase using a linear mixed model. Here, there was small to moderate evidence that stimulus-related activity was stronger for complex compared to simple stimuli (mean effect complex $=0.009$, mean effect simple $=0.001 ; t$ $=3.52, p=0.005, d=0.49,95 \% \mathrm{Cl}=[0.21-0.77])$. During the delay phase, stimulus-related activity was virtually absent for both stimulus classes, consequently there were also no differences in stimulus- 
related activity between the classes. Random effects residuals of the linear mixed model are reported in SI Table 3.

We were also interested whether the number of stimulus-representing neurons was driven by reward contingencies, i.e. if neurons represented stimuli associated with high reward more often. Of the 20 cells modulated by the complex stimuli, 12 cells coded for the high rewarded stimuli whereas eight cells were active in the presence of low rewarded stimuli. No significant difference could be detected between them $\left.\chi_{(1)}^{2}=0.8, p>0.250\right)$ indicating that reward probability did not drive stimulus-related activity in the NCL population. 
A

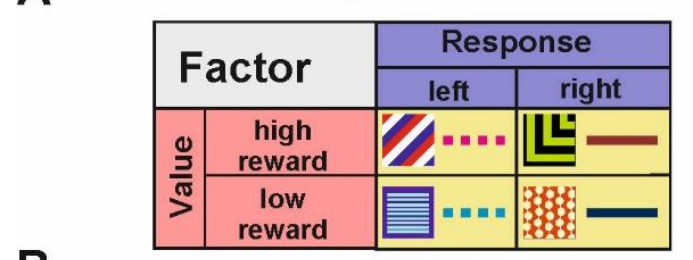

B

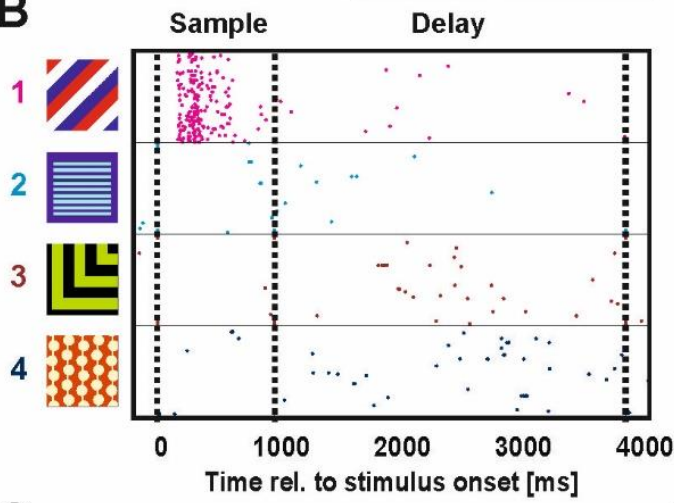

C

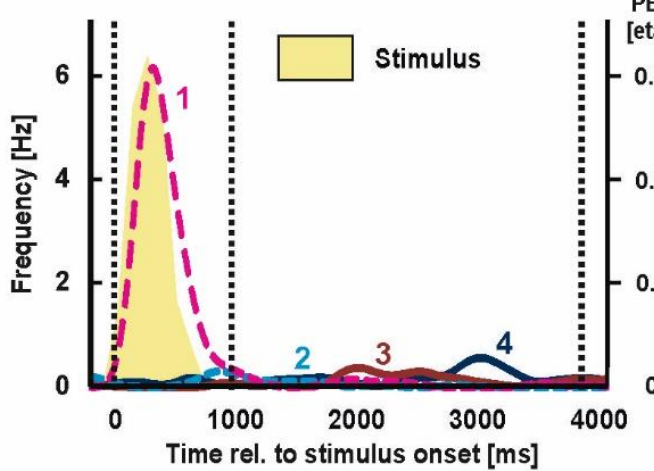

D

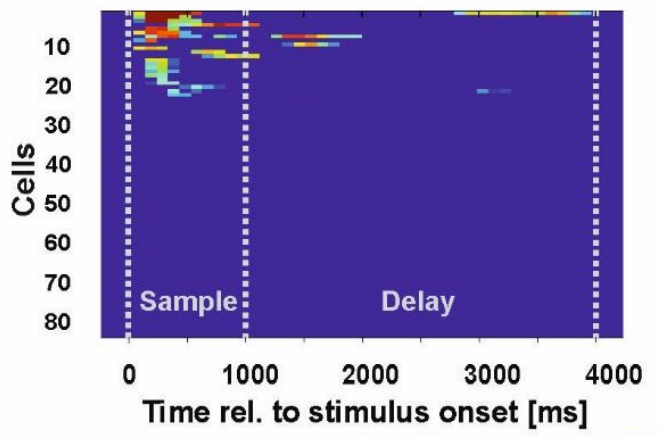

Simple stimuli

\begin{tabular}{|c|c|c|c|}
\hline \multirow{2}{*}{ Factor } & \multicolumn{2}{c|}{ Response } \\
\cline { 2 - 4 } & left & right \\
\hline \multirow{2}{*}{$\frac{0}{\frac{D}{N}}$} & $\begin{array}{c}\text { high } \\
\text { contrast }\end{array}$ & & \\
\cline { 2 - 3 } & $\begin{array}{c}\text { low } \\
\text { contrast }\end{array}$ & & \\
\hline
\end{tabular}

Sample Delay

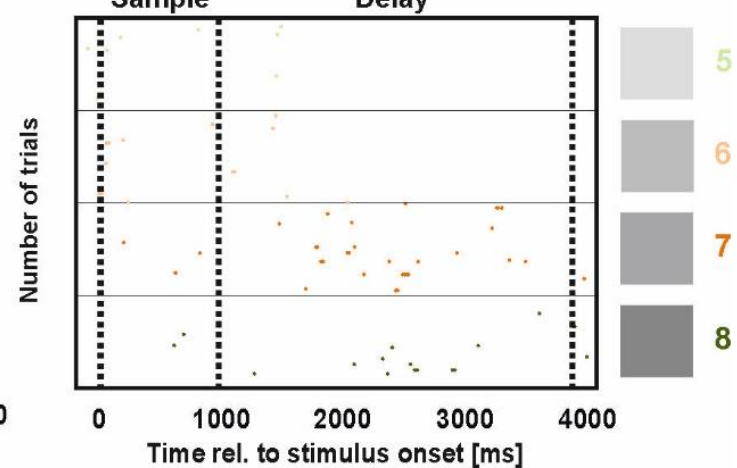

PEV
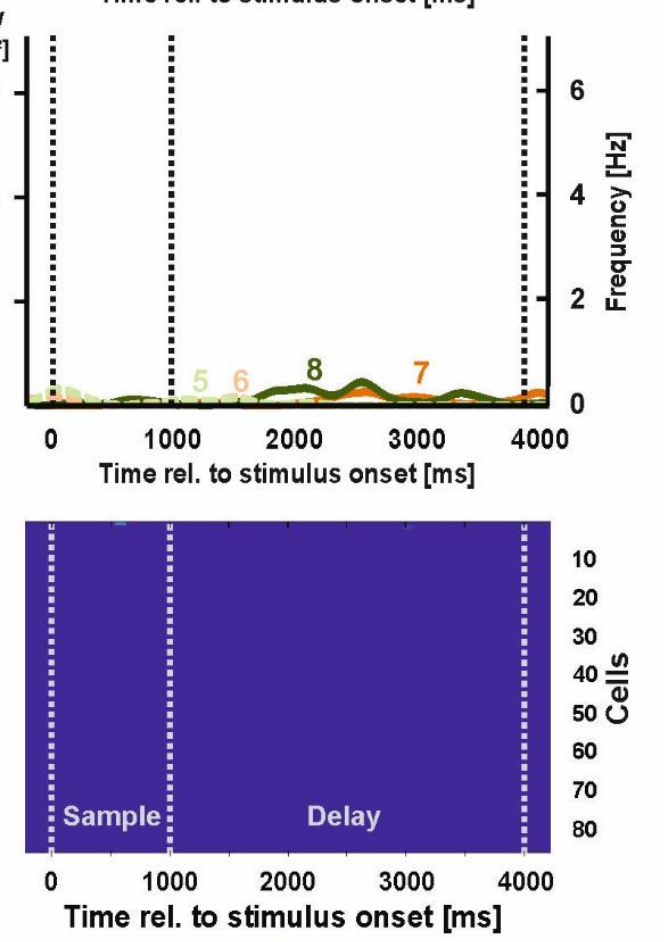

Percent Explained Variance $\left[\mathrm{eta}^{2}\right]$

$\begin{array}{ll}0.03 & 0.05\end{array}$

0.1

0.2

Figure 3. Example neuron and population response for stimulus-related activity in the NCL. A) The rationale of the ANOVA for the physiological data. Stimuli were either associated with a left (dashed lines) or right choice (solid lines, factor choice) or with the higher or lower net outcome due to different reward probabilities in the complex stimulus class (left panel) or discrepancies in contrast for the simple stimulus class (right panel). The colors in the figure represent the different activity patterns of NCL neurons (stimulus = yellow, value $=$ red, choice $=$ blue). B) Raster plot of a stimulus representing example neuron. Dashed vertical lines indicate borders of the phases. This neuron specifically responded to one of the high rewarded complex stimuli during the sample phase (left) and to no stimulus from the simple stimuli (right). C) Spike density function (SDF) of the example neuron shown in B). The numbers of the line plots correspond with one of the eight experimental stimuli. The percent explained variance (PEV) by the relevant activation type is presented behind the SDF. D) Population response for stimulus-related activity of all individual neurons for complex (left panel) and simple stimuli trials (right panel). Cells that did not exhibit any activity according to the ANOVA during any phase ( $\mathrm{n}=22$ cells) were excluded from the plot. Only above threshold firing $\left(\eta_{p}^{2}>0.03\right)$ is shown. 


\section{Value-related activity}

The second aspect captured by our analysis was value-related activity, i.e. activity differences between high and low reward complex stimuli or differences between high and low contrast simple stimuli. An example neuron representing value differences for complex stimuli is shown in Figure 4B (raster plot) and $4 \mathrm{C}$ (spike density function or SDF). This neuron differentiated significantly between stimuli of high and low reward probability during the sample phase (value effect size is highlighted in red).

The results for value-related activity of each neuron are presented in Figure 4D. Value coding was most prevalent during the sample phase and could exclusively be found for complex stimuli. Comparing the average effect of value-related activity between both stimulus classes during the sample phase revealed small evidence for stronger effects for complex stimuli compared to simple stimuli (mean effect complex $=0.005$, mean effect simple $<0.001, t=2.22, p=0.028, d=0.31,95 \% \mathrm{Cl}=[0.03-$ $0.58]$ ). This was also true for the first second of the delay phase (mean effect complex $=0.003$, mean effect simple $<0.001 ; t=2.56, p=0.011, d=0.35,95 \% \mathrm{Cl}=[0.08-0.63])$. Value-related activity was absent further on during the task (see Figure 4D and Table 1). Thus, no differences in value-related activity were found during these task periods. Random effects residuals of the linear mixed model are reported in SI Table 3. 
A

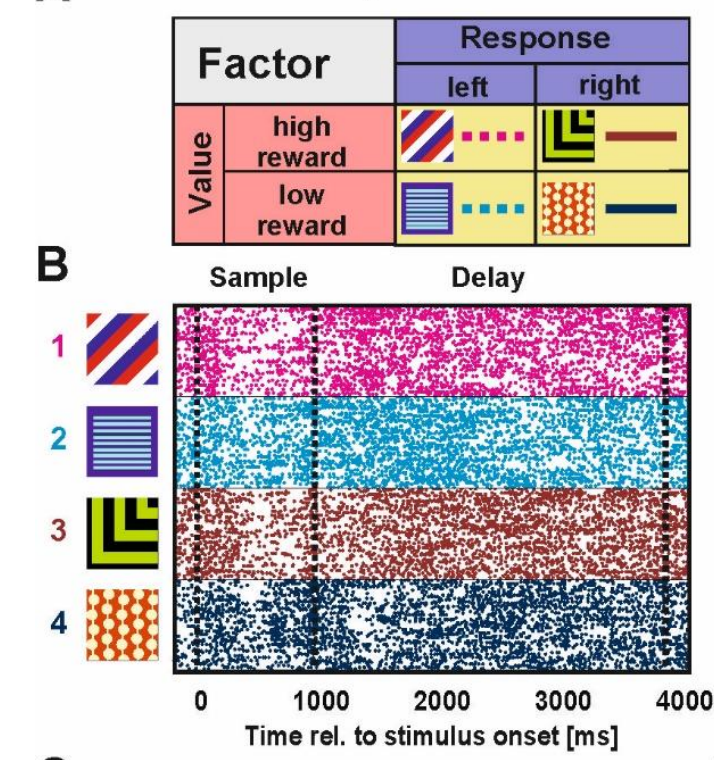

Simple stimuli

\begin{tabular}{|c|c|c|c|}
\hline \multicolumn{2}{|c|}{ Factor } & \multicolumn{2}{c|}{ Response } \\
\cline { 2 - 4 } & left & right \\
\hline \multirow{2}{*}{$\frac{0}{\sqrt{N}}$} & $\begin{array}{c}\text { high } \\
\text { contrast }\end{array}$ & & \\
\cline { 2 - 3 } & $\begin{array}{c}\text { low } \\
\text { contrast }\end{array}$ & & \\
\hline
\end{tabular}

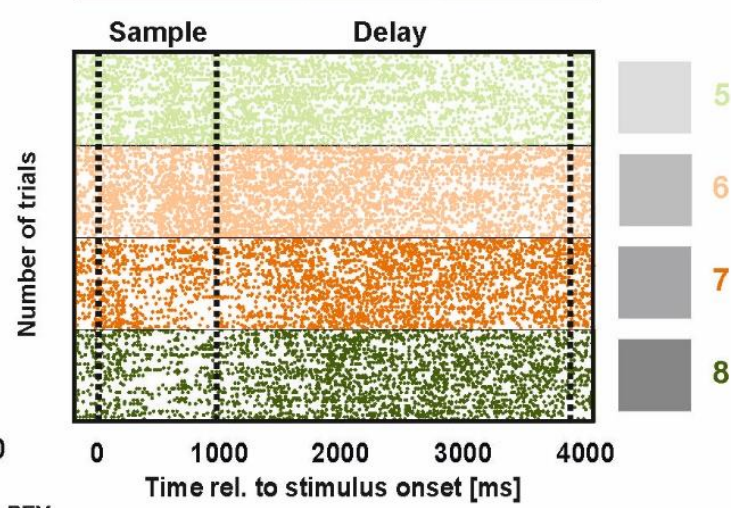

C

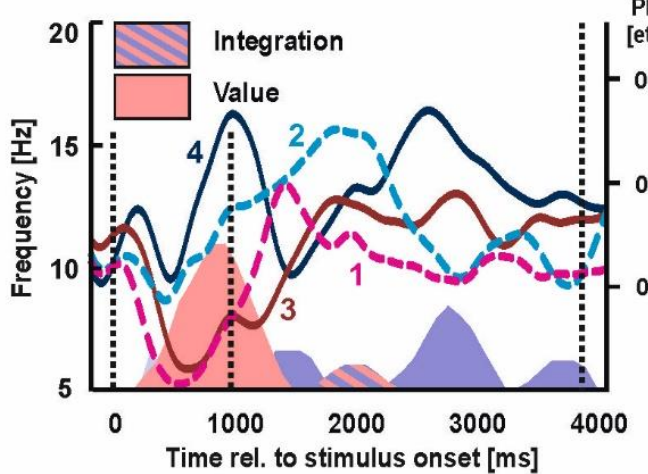

D
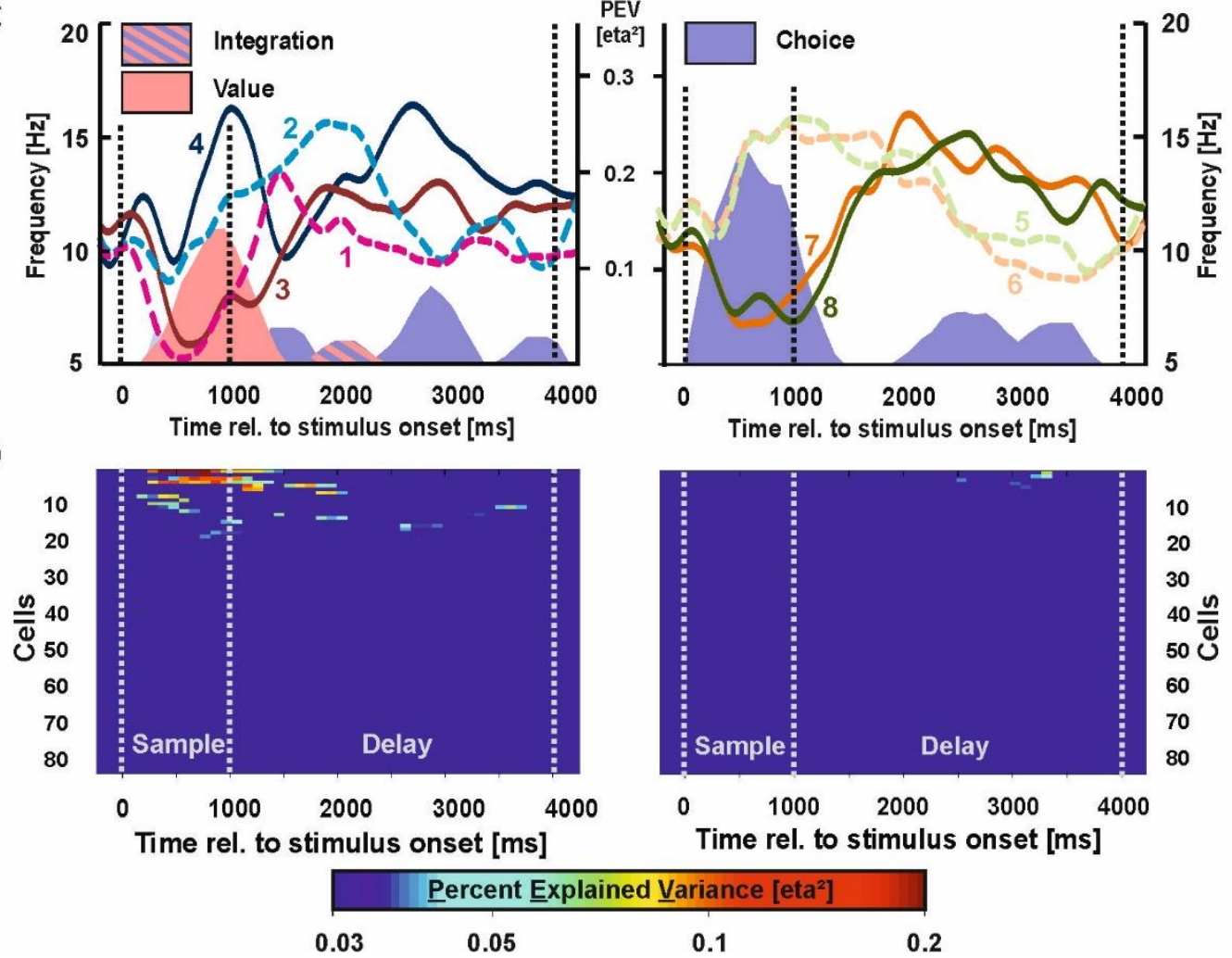

Figure 4. Example neuron and population response for value-related activity in the NCL. A) The rationale of the ANOVA as described in Figure 3. B) Raster plot of a value representing neuron. This neuron differentiated between low and high reward stimuli during the sample phase for complex stimuli (left). For simple stimuli, the upcoming choice was represented during the sample phase (right). During the delay, this neuron demonstrated a choice code for complex and simple stimuli alike C) Spike density function of the example neuron shown in B). The PEV by the relevant activity type is presented behind the SDF. D) Population response for value-related activity of all individual neurons for trials in which complex (left panel) and simple stimuli (right panel) were presented. 


\section{Integrative representations of value and choice}

The third aspect we analyzed was the interaction between the factors value and choice. This type of integrative representations arose whenever a single neuron represented more than one single stimulus (stimulus-related activity) or when value-related activity switched to a choice-based pattern within the very same cell. An example neuron representing two stimuli simultaneously resulting in a significant interaction effect is shown in Figure 5B (raster) and 5C (SDF). During the sample phase, this neuron initially increased its firing rate when a stimulus was presented. However, this activity was either up- or downregulated when a stimulus of high reward probability was presented (interaction effect is highlighted in blue/red).

The results for integrative representations of each individual neuron are presented in Figure 5D (left: complex stimuli, right: simple stimuli). Integrative representations were most prevalent during the sample phase and could almost exclusively be found for complex stimuli. Comparing the average effect of integrative representations between both stimulus classes during the sample phase revealed small evidence for stronger activity for complex compared to simple stimuli (mean effect complex $=0.002$, mean effect simple $<0.001 ; t=2.97, p=0.003, d=0.41,95 \% \mathrm{Cl}=[0.14-0.69])$. This was also true for the first second of the delay phase (mean effect complex $=0.002$, mean effect simple $<0.001 ; t=2.81$, $p=0.005, d=0.39,95 \% \mathrm{Cl}=[0.11-0.67])$. Interaction representations were no longer found further on during the task (see Figure 5D and Table 1). Thus, no differences were present during the second and third second of the delay. Random effects residuals of the linear mixed model are reported in SI Table 3. 
A

Complex stimuli

\begin{tabular}{|c|c|c|c|}
\hline \multirow{2}{*}{\multicolumn{2}{|c|}{ Factor }} & \multicolumn{2}{|c|}{ Response } \\
\hline & & left & right \\
\hline \multirow{2}{*}{$\frac{\frac{0}{2}}{\frac{D}{\pi}}$} & $\begin{array}{c}\text { high } \\
\text { reward }\end{array}$ & $28=\cdots$ & 는 \\
\hline & $\begin{array}{c}\text { low } \\
\text { reward }\end{array}$ & 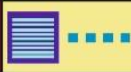 & 尔 \\
\hline
\end{tabular}

B
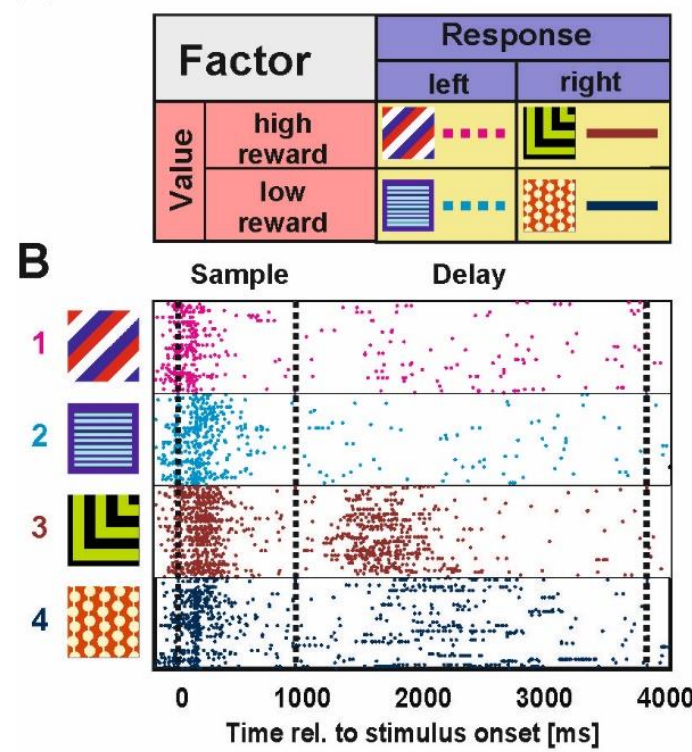

C

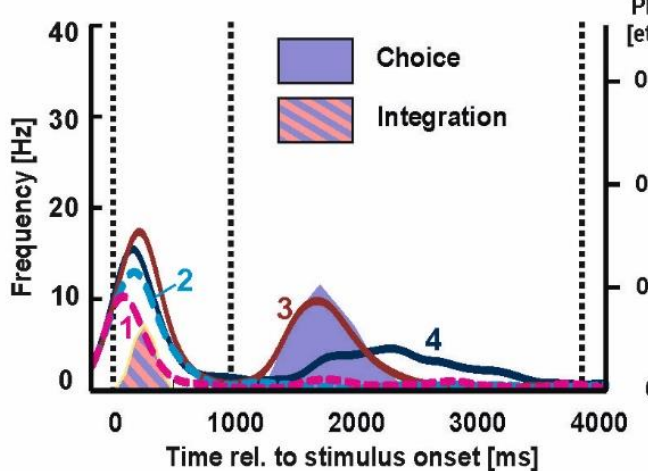

D

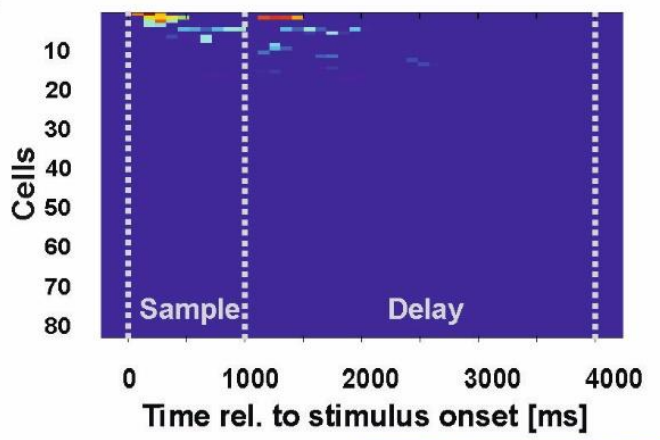

Simple stimuli

\begin{tabular}{|c|c|c|c|}
\hline \multirow{2}{*}{ Factor } & \multicolumn{2}{c|}{ Response } \\
\cline { 2 - 4 } & left & right \\
\hline \multirow{2}{*}{$\frac{\mathrm{J}}{\mathrm{N}}$} & $\begin{array}{c}\text { high } \\
\text { contrast }\end{array}$ & & \\
& $\begin{array}{c}\text { low } \\
\text { contrast }\end{array}$ & & \\
\hline
\end{tabular}
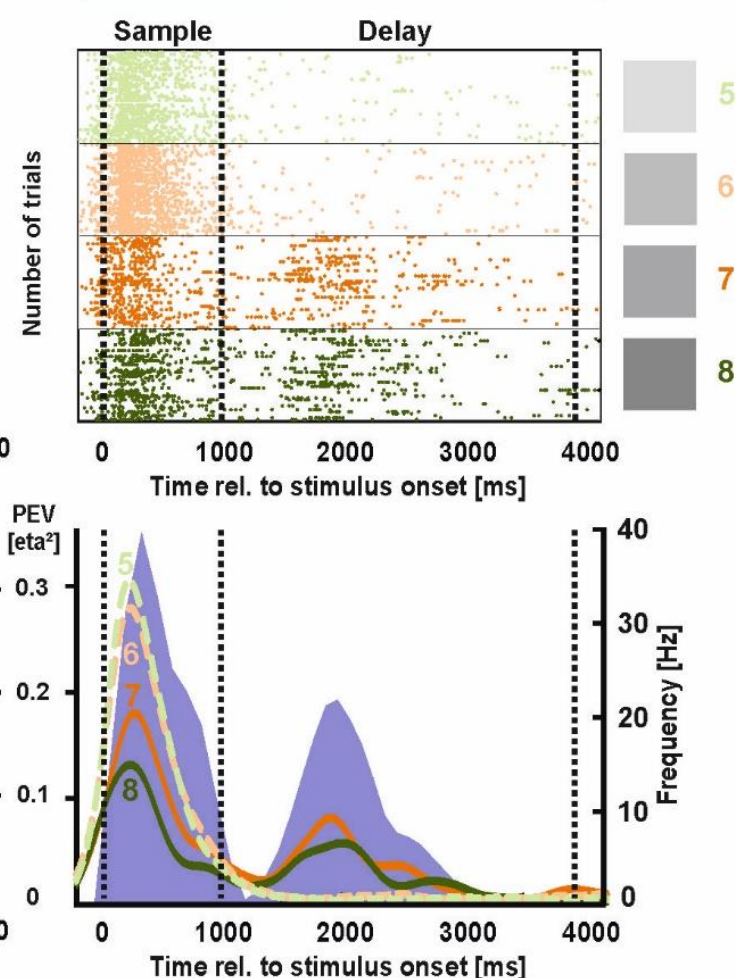

$$
\begin{array}{|cccc|}
\hline & \multicolumn{3}{|c|}{\text { Percent Explained Variance [eta } \left.{ }^{2}\right]} \\
0.03 & 0.05 & 0.1 & 0.2
\end{array}
$$

Figure 5. Example neuron and population response for integrative representations in the NCL. A) The rationale of the ANOVA as described in Figure 3. B) Raster plot of an example neuron illustrating integrative representations. For complex stimuli, this neuron increased its firing rate for one high reward stimulus whereas it decreased the firing rate for the other high reward stimulus compared to both low reward stimuli resulting in a significant interaction effect during the sample phase (left). For simple stimuli, choice-related activity was present already during the sample phase (right). During the delay, this neuron demonstrated a choice code for complex and simple stimuli alike. C) Spike density function of the example neuron shown in B). The PEV by the relevant coding type is presented behind the SDF. D) Population response for integrative representations of all individual neurons for trials in which complex (left panel) and simple stimuli (right panel) were presented. 


\section{Choice-related activity}

The last activity type we investigated was choice-related activity - a neural response associated with the side of the animals' response. To verify that this activity was indeed associated with the animal's subsequent decision, we compared correct and incorrect trials in a supplementary analysis (SI Figure 7 and 8). An example neuron demonstrating choice-related activity is depicted in Figure 6B (raster) and 6C (SDF). For simple stimuli, this neuron did not show any relevant activity changes during the sample phase whereas it exhibited stimulus-related activity for complex stimuli. During the delay phase, this neuron differentiated between left and right decisions both for complex and simple stimuli.

The results for choice-related activity of each individual neuron are presented in Figure 6D (left: complex stimuli, right: simple stimuli). Choice-related activity in the NCL was found extensively, but its extent differed notably between the stimulus classes. Comparing the average effect of choice-related activity between both stimulus classes during the sample phase revealed small evidence for a stronger effect of simple compared to complex stimuli (mean effect complex $=0.001$, mean effect simple $=$ $0.008 ; t=2.59, p=0.010, d=0.36,95 \% \mathrm{Cl}=[0.08-0.64])$. Across the delay phase, effect sizes of choice-related activity did not differ between the different stimulus sets at any point in time. Random effects residuals of the linear mixed model are reported in SI Table 3. 
A

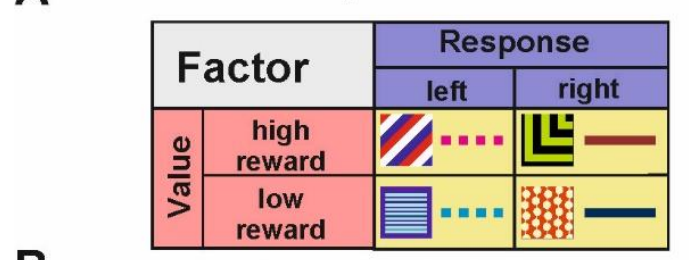

B

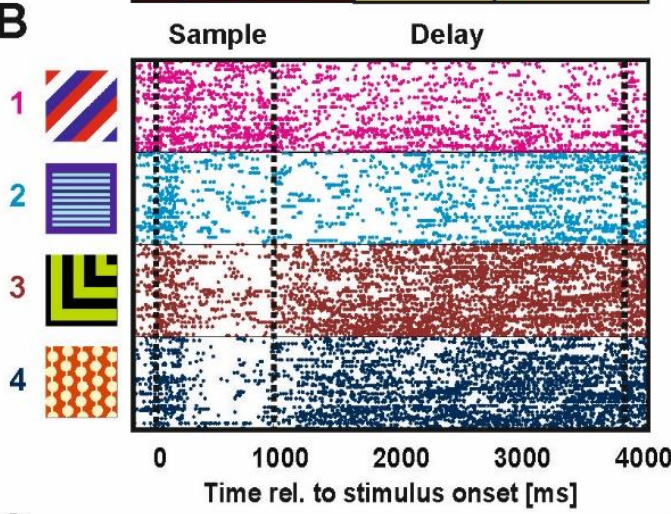

C

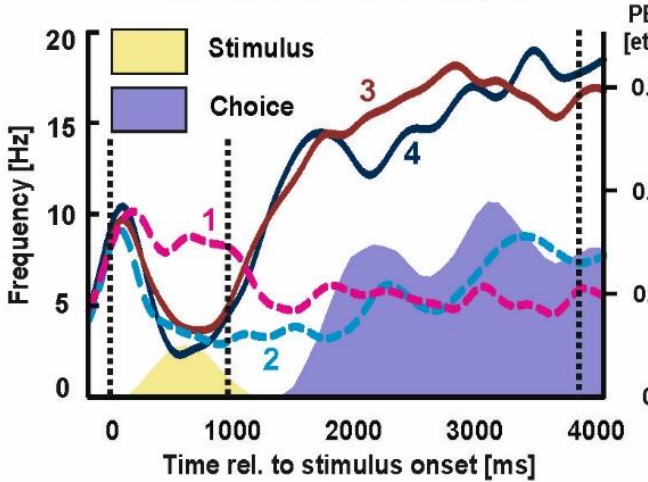

D

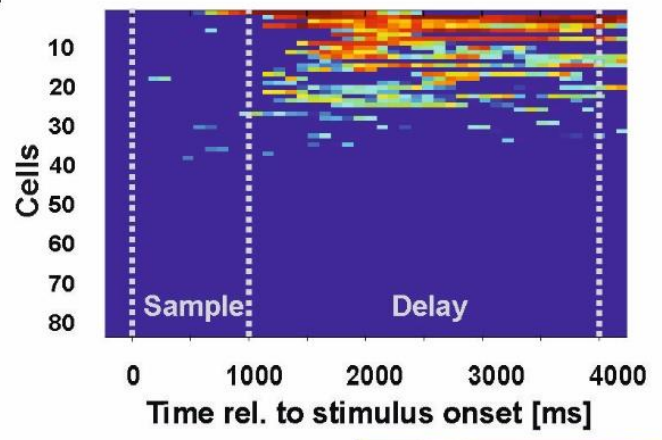

Simple stimuli

\begin{tabular}{|c|c|c|c|}
\hline \multirow{2}{*}{ Factor } & \multicolumn{2}{c|}{ Response } \\
\cline { 2 - 4 } & left & right \\
\hline \multirow{2}{*}{$\frac{\mathrm{J}}{\mathrm{N}}$} & $\begin{array}{c}\text { high } \\
\text { contrast }\end{array}$ & & \\
\cline { 2 - 3 } & $\begin{array}{c}\text { low } \\
\text { contrast }\end{array}$ & & \\
\hline
\end{tabular}

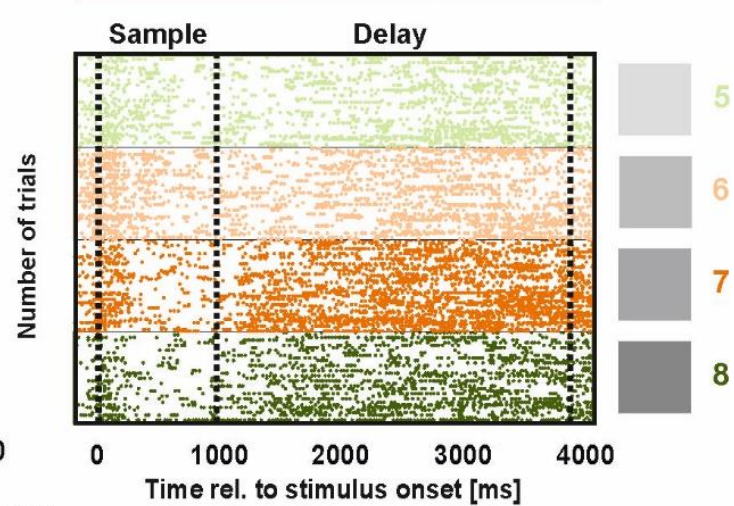

PEV
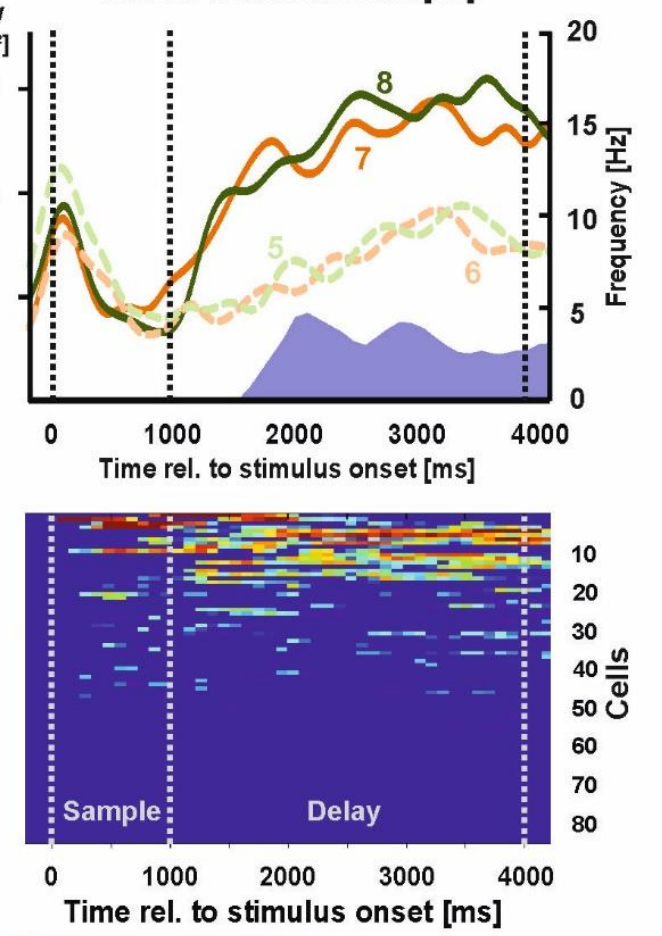

Percent Explained Variance [eta $\left.{ }^{2}\right]$
0.03
0.05
0.1
0.2

Figure 6. Example neuron and population response for choice-related activity in the NCL. A) The rationale of the ANOVA as described in Figure 3. B) Raster plot of an example neuron demonstrating choice-related activity. For both complex and simple stimuli, this neuron differentiated between stimuli associated with a left and right choice during the delay phase. For complex stimuli, the neuron furthermore showed stimulus-related activity during the sample phase (left). C) Spike density function of the example neuron shown in B). The PEV by the relevant coding type is presented behind the SDF. D) Population response for choice-related activity of all individual neurons for trials in which complex (left panel) and simple stimuli (right panel) were presented. 


\section{Neural activation schemes}

So far, our analysis was based on the population response for single task parameters such as value or choice but it did not investigate if individual neurons dynamically represent different task parameters, a phenomenon known as neural multiplexing (Mante et al., 2013). To investigate whether NCL neurons were encoding only one task aspect (i.e., solely stimulus, value, interaction or choice representations) or were engaged in the representation of multiple aspects at different stages of the task, we tracked task-related activity patterns of individual neurons over time and categorized them accordingly.

As evident from the example neurons shown in Figure $4 B / C, 5 B / C$ and $6 B / C$, individual neurons were not limited to one type of activation pattern but employed strong multiplexing resulting in dynamic changes from the sample to the delay phase when presented with complex stimuli. For simple stimuli, these neurons exclusively represented choice-related activity.

Based on the results of the ANOVA, we created four post hoc categories to classify individual neurons according to their firing pattern dynamics across the sample and delay phase:

1. Early choice: The upcoming choice was represented already during the sample phase. No stimulus, value or integrative representation is observed at any point during the task. An example neuron is depicted in Figure 7A1 (raster) and 7A2 (SDF).

2. Late choice: The upcoming choice was represented after the sample phase had ended. No stimulus, value or integrative representation is observed at any point during the task. An example neuron is depicted in Figure 7B1 (raster) and 7B2 (SDF).

3. Stimulus - No choice: Neurons that demonstrated stimulus, value or integrative representations, but no choice-related activity. An example neuron is depicted in Figure 7C1 (raster) and 7C2 (SDF). 
bioRxiv preprint doi: https://doi.org/10.1101/2021.09.10.459776; this version posted September 11, 2021. The copyright holder for this preprint (which was not certified by peer review) is the author/funder, who has granted bioRxiv a license to display the preprint in perpetuity. It is made available under aCC-BY-NC 4.0 International license.

4. Stimulus - Choice: Neurons that demonstrated stimulus, value or integrative representations initially during the trial and then dynamically switched to a choice representation later in the trial. An example neuron is depicted in Figure 7D1 (raster) and 7D2 (SDF).
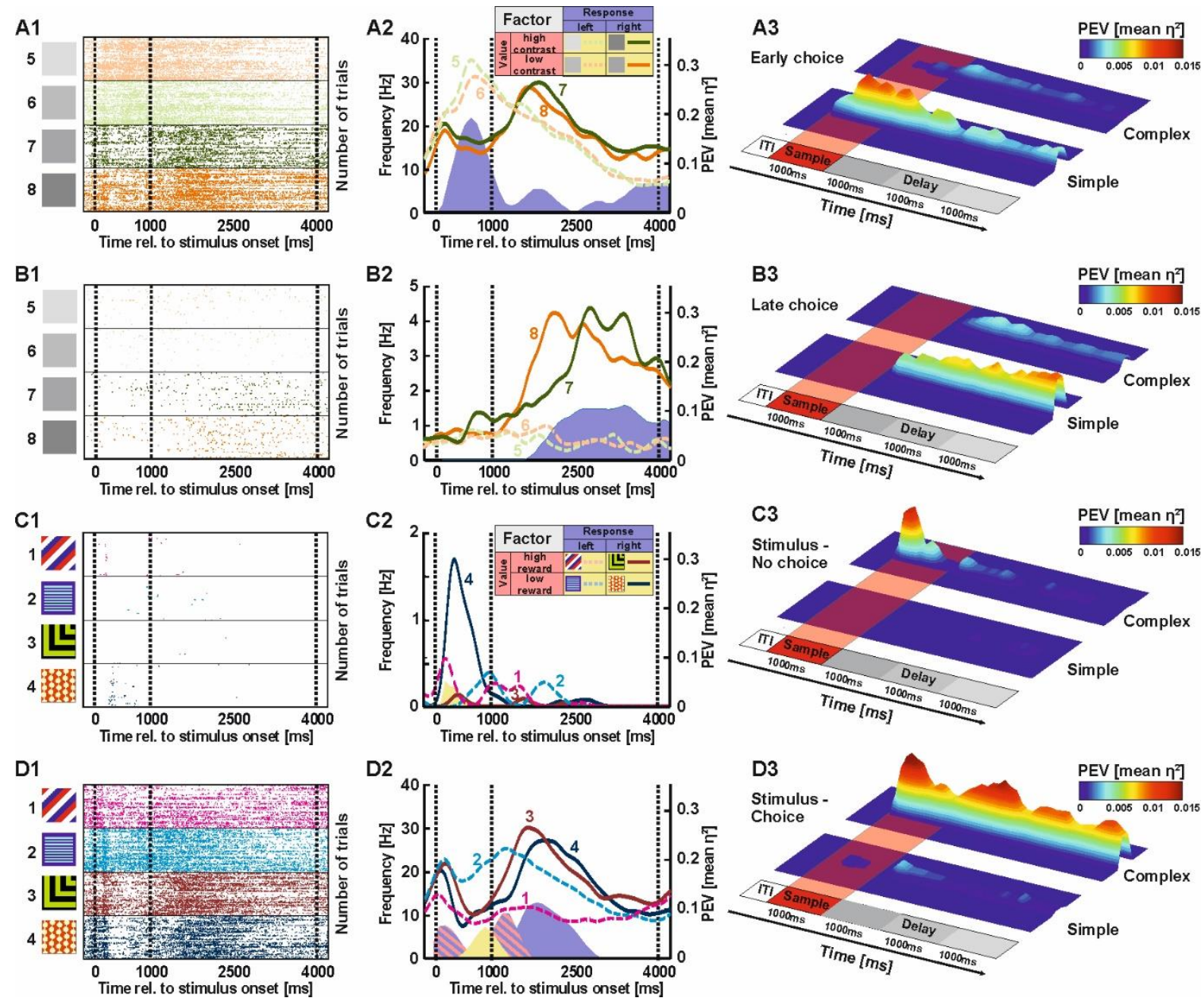

Figure 7. Neuronal coding schemes in the NCL. A) The first category comprised neurons that encoded the upcoming decision already during the sample phase ("early choice"). A1) Raster plot of an example neuron that differentiated between left and right choices during sample and delay phase for the simple stimuli. A2) According SDF and effect sizes of the example neuron. A3) Population average for all neurons demonstrating "early choice" representations for both the simple and complex stimuli. B) The second category comprised neurons that represented the upcoming decision from delay phase onset onwards ("late choice"). B1) Raster plot of an example neuron that differentiated between left and right choices during the delay for the simple stimuli. B2) According SDF and effect sizes of the example neuron. B3) Population average for all neurons demonstrating "late choice" representations for both the simple and complex stimuli. C) The third category comprised neurons that encoded solely task parameters not associated with the upcoming choice, i.e. stimulus, value and/or integrative representations during either sample or delay phase ("stimulus - no choice"). C1) Raster plot of an example neuron that demonstrated stimulus-related activity during the sample phase for one complex stimulus. C2) According SDF and effect sizes of the example neuron. (3) Population average for all neurons demonstrating "stimulus - no choice" representations for both the simple and complex stimuli. D) The fourth category comprised neurons that initially encoded representations not associated with the upcoming choice, i.e. stimulus, value and/or integrative representations, but later switched to choicerelated activity patterns ("stimulus - choice"). D1) Raster plot of an example neuron that demonstrated stimulus-related and integrative representations during the sample and early delay phase for complex stimuli. The neuron then dynamically switched to choice-related activity during the delay phase. D2) According SDF and effect sizes of the example neuron. D3) Population average for all neurons demonstrating "stimulus - choice" representations for both the simple and complex stimuli. 
The two stimulus classes differed with regard to the number of "early choice" and "late choice" neurons. Significantly fewer neurons demonstrated early choice-related activity with complex then with simple stimuli (complex: six neurons, simple: 21 neurons, $\chi^{2}{ }_{(1)}=9.58, p=.002$ ). The same was true for "late choice" representations (complex: 13 neurons, simple: 26 neurons, $\chi^{2}(1)=5.33, p=.021$ ). Thus, representations of choice were significantly more prevalent for simple stimuli. Interestingly, "early choice" neurons demonstrated significantly higher effects of choice-related activity at the beginning than at the end of the delay for simple stimuli $\left(t_{(9)}=8.70, p<0.001\right.$, see Figure $\left.7 \mathrm{~A} 3\right)$ indicating that the strength of the choice-related activity decayed after an early onset. Activity levels of "late choice" neurons did not significantly decay throughout the delay (Figure 7B3).

We then compared the number of active cells for the "stimulus - no choice" and the "stimulus - choice" category between the two stimulus classes. Here, 33 cells demonstrated "stimulus - no choice" representations when confronted with complex stimuli compared to four cells when confronted with simple stimuli $\left(\chi^{2}(1)=9.58, p<.001\right.$, see Figure 7C3 for population results). "Stimulus - choice" neurons were also more prevalent when the animals were confronted with complex compared to simple stimuli (complex: 16 neurons, simple: five neurons, $\chi_{(1)}^{2}=6.41, p=.011$ ). In contrast to "early choice" neurons, activity levels did not decay from early to late stages of the delay in neurons employing such a stimuluschoice representation when complex stimuli were presented $\left(t_{(9)}=0.60, p=0.561\right.$, Figure 7D3).

Overall, NCL neurons show multiplexing by dynamically switching from stimulus, value or integrative representations to choice-related activity. However, this coding scheme was exclusively found when complex stimuli were presented. In this case, the subsequent choice component was maintained at a stable level throughout the entire delay period. For simple stimuli, neuronal multiplexing was entirely absent since neurons did not represent stimulus, value or integrative representations at all. Instead, choice-related activity emerged already during the presentation of simple stimuli. Population activity of these "early choice" neurons subsequently degraded over the delay phase. 


\section{Discussion}

In the present study, we investigated the effects of stimulus-complexity on working memory performance using both behavioral and neurophysiological approaches in pigeons. In line with our hypothesis, complex stimuli that were rich in color and spatial information could be maintained better in working memory compared to simple stimuli void of visual features except for luminance. This distinction was associated with a clear difference between the cellular representations of these stimulus classes. NCL neurons represented only idiosyncratic features of complex stimuli such as their value or physical identity during the sample phase. Only later, during the delay period the upcoming choice was represented. Importantly, the representation of different task parameters (e.g. stimulus and choice) occurred within single neurons illustrating neuronal multiplexing. Simple stimuli, on the other hand, were never represented in NCL. Instead, we only recorded signals reflecting the upcoming choice even while the images were still visible to the animal. Since we exclusively discovered choicerelated activity for simple stimuli, no neuronal multiplexing could be detected.

The idea that stimulus features impact working memory performance is rather recent. Results that some hues are memorized more precisely than others or that cardinal directions are easier to memorize than other orientations can probably be explained by categorization that could depend on stimulus statistics (Girshick et al., 2011; Bae et al., 2014; 2015, Panichello et al., 2019). These findings have usually been conceptualized in the scope of computational models investigating capacity limits (Fougnie et al., 2010, Lilburn et al., 2019), noise accumulation (Rademaker et al., 2018), or discrete memory storage (Pratte et al., 2017, van den Berg et al., 2012). Importantly, all these frameworks indicate a clear relation between the identity of a specific visual stimulus and memory performance that is grounded in a systematic difference of the stimulus' neural representation. Our results support this notion as the enhanced performance for complex compared to the simple stimuli could be linked to a differential recruitment of neural populations for the two stimulus classes. Complex stimuli offered a large number of idiosyncratic visual features that could have aided in bringing the working memory 
bioRxiv preprint doi: https://doi org/10.1101/2021.09.10.459776; this version posted September 11,2021 . The copyright holder for this preprint (which was not certified by peer review) is the author/funder, who has granted bioRxiv a license to display the preprint in perpetuity. It is made available under aCC-BY-NC 4.0 International license.

representation into a stable state. A potential explanation how this occurred on the neural level could relate to different activity schemes depending on the presented stimulus class: we exclusively found neuronal multiplexing when complex stimuli were presented. Here, individual neurons represented a multitude of task parameters not only at different points during the trial but also simultaneously with regards to integrative representations. Thus, representations of complex stimuli were of higher dimensionality in the NCL compared to those of simple stimuli.

High dimensional coding by neurons has been suggested to be associated with a facilitated read-out by downstream neurons (Fusi et al., 2017). Since active maintenance in working memory relies on bursting populations rather than single neurons carrying the information, especially across long delays (Lundqvist et al., 2016), it seems feasible that a facilitated read-out through high dimensional representations aids the transmission of said information. Furthermore, both in rodents and primates, studies investigating high dimensional coding properties of (pre-)frontal cortices during the execution of higher cognitive tasks have demonstrated that this dimensionality collapses in error trials indicating that it is subserving goal-directed behavior (Rigotti et al., 2013; Balaguer-Ballester et al., 2011). Overall, our physiological findings therefore suggest that high dimensional representations are tied to the presented stimulus material. A recent study has furthermore demonstrated that attention and working memory share a common neural basis in the PFC (Panichello and Buschman, 2021) hinting at the possibility that the presence of manifold stimulus features increased attention towards the stimuli enhancing the neural representation in working memory.

A consequence of the differential activity pattern during the stimulus presentation is the concomitant difference in the onset of neural activity reflecting the upcoming choice. If the switch from stimulusrelated to choice-related activity is taken as an indicator of decision time (see Shadlen and Newsome, 2001; Kim and Shadlen, 1999; Gold and Shadlen, 2000), the decision happened significantly later for complex stimuli (almost exclusively after delay onset) shortening active maintenance of the choicerelated activity in working memory. Longer maintenance times have been demonstrated to result in a decay of the memory trace, which is hypothesized to be a consequence from stochastic neural noise 
causing the degradation of the stored memory over maintenance time (Barrouillet et al., 2018; Burak and Fiete, 2012). For simple stimuli, we observed no stimulus- or value-related activity during the sample phase. Rather, choice-related activity emerged much earlier already during stimulus presentation and as a direct result, maintenance time for the upcoming choice was prolonged. This could have resulted in increased trace decay compared to the complex stimuli since there was an increased opportunity for noise to accumulate and for interference to occur.

In our study, we provide evidence that stimulus material is influencing working memory. We found that the increased stimulus-complexity of a visual stimulus positively affects working memory performance compared to low stimulus-complexity. Our complementary neuronal data indicate that the neural representations associated with our two stimulus classes differed substantially. For complex stimuli, we found high dimensional multiplex activity patterns as well as a delayed onset of choicerelated activity in the NCL population. For simple stimuli, choice-related activity was immediately present and the population activity was markedly low dimensional. These differences in representation could provide an account for the behavioral differences observed. Since working memory research has largely focused on memory load rather than the stimulus material, our study highlights the importance to carefully select the stimulus material. 


\section{Acknowledgments}

This study was funded by the Deutsche Forschungsgemeinschaft (DFG, German Research Foundation)

- Projektnummer 122679504 SFB 874 (project B5), Projeknummer 316803389 SFB 1280 (projects A01,

A14, F01), Gu 227/16-1 and the Research Training Group "Situated Cognition" (GRK 2185/1).

\section{Author contributions}

R.P. conceived and supervised the experiments, analyzed the data, discussed the result patterns and wrote the manuscript. J.P. performed the experiments, analyzed the data, discussed the result patterns and wrote the manuscript. A.H.A. and S.C. performed the stimulus analyses and reviewed the manuscript. J.R. consulted on data analyses, discussed the result patterns and reviewed the manuscript. C.S.S. conducted behavioral experiments. M.C.S. conceived the experiment, consulted on data analyses and reviewed the manuscript. O.G. conceived the experiments, consulted on data analyses, discussed the result patterns and reviewed the manuscript.

\section{Declaration of interests}

The authors declare no competing interests. 


\section{References}

Azizi, A.H., Pusch, R., Koenen, C., Klatt, S., Bröcker, F., Thiele, S., Kellermann, J., Güntürkün, O., and Cheng, S. (2019). Emerging category representation in the visual forebrain hierarchy of pigeons (Columba livia). Behav. Brain Res. 356, 423-434.

Bae, G.Y., Olkkonen, M., Allred, S.R., Wilson, C., and Flombaum, J.I. (2014). Stimulus-specific variability in color working memory with delayed estimation. J. Vis. 14, 7.

Bae, G.Y., Olkkonen, M., Allred, S.R., and Flombaum, J.I. (2015). Why some colors appear more memorable than others: A model combining categories and particulars in color working memory. $J$. Exp. Psychol. Gen. 144, 744-763.

Balaguer-Ballester, E., Lapish, C.C., Seamans, J.K., and Durstewitz, D. (2011). Attracting dynamics of frontal cortex ensembles during memory-guided decision-making. PLoS Comput. Biol. 7, e1002057.

Balakhonov, D., and Rose, J. (2017). Crows rival monkeys in cognitive capacity. Sci. Rep. 7, 8809.

Barrouillet, P., Uittenhove, K., Lucidi, A., and Langerock, N. (2018). On the sources of forgetting in working memory: The test of competing hypotheses. Q. J. Exp. Psychol. 71, 1714-1733.

Bilkey, D.K., and Muir, G.M. (1999). A low cost, high precision subminiature microdrive for extracellular unit recording in behaving animals. J. Neurosci. Methods 92, 87-90.

Bilkey, D.K., Russell, N., and Colombo, M. (2003). A lightweight microdrive for single-unit recording in freely moving rats and pigeons. Methods 30, 152-158.

Burak, Y., and Fiete, I.R. (2012). Fundamental limits on persistent activity in networks of noisy neurons. Proc. Natl. Acad. Sci. 109, 17645-17650.

Buschman, T.J., and Miller, E.K. (2007). Top-down versus bottom-up control of attention in the prefrontal and posterior parietal cortices. Science, 315, 1860-1862.

Buschman T.J., Siegel M., Roy J.E., and Miller E.K. (2011). Neural substrates of cognitive capacity limitations. Proc. Natl. Acad. Sci., 108, 11252-11255.

Cohen, J. (1988). Statistical power analysis for the behavioral sciences. New York: Lawrence Erlbaum Associates.

Constantinidis, C., and Klingberg, T. (2016). The neuroscience of working memory capacity and training. Nat. Rev. Neurosci. 17, 438-49.

Conway, A.R.A., Kane, M.J., and Engle, R.W. (2003). Working memory capacity and its relation to general intelligence. Trends Cogn. Sci. 7, 547-552.

D'Esposito, M., and Postle, B.R. (2015). The cognitive neuroscience of working memory. Annu. Rev. Psychol. 66, 115-142.

Diekamp, B., Kalt, T., and Güntürkün, O. (2002). Working memory neurons in pigeons. J. Neurosci. 22, RC210. 
Fougnie, D., Asplund, C.L., and Marois, R. (2010). What are the units of storage in visual working memory? J. Vis. 10, 27.

Funahashi S. (2015). Functions of delay-period activity in the prefrontal cortex and mnemonic scotomas revisited. Front. Syst. Neurosci. 9, 2.

Funahashi S. (2017). Working Memory in the Prefrontal Cortex. Brain Sci., 7, 49.

Fusi, S., Miller, E.K., and Rigotti, M. (2016). Why neurons mix: high dimensionality for higher cognition. Curr. Opin. Neurobiol. 37, 66-74.

Fuster, J.M., and Alexander, G.E. (1971). Neuron activity related to short-term memory. Science 173, 652-654.

Gegenfurtner, K.R., and Rieger, J. (2000). Sensory and cognitive contributions of color to the recognition of natural scenes. Curr. Biol. 10, 805-808.

Girshick, A.R., Landy, M.S., and Simoncelli, E.P. (2011). Cardinal rules: visual orientation perception reflects knowledge of environmental statistics. Nat. Neurosci. 14, 926-932.

Gold, J.I., and Shadlen, M.N. (2000). Representation of a perceptual decision in developing oculomotor commands. Nature 404, 390-394.

Güntürkün, O. (2000). Sensory physiology: Vision. In: G.C. Whittow (Ed.), Sturkie's Avian Physiology, 119. Orlando: Academic Press.

Güntürkün, O., Stüttgen, M.C., and Manns, M. (2014). Pigeons as a model species for cognitive neuroscience. e-Neuroforum 5, 86-92.

Güntürkün, O., Verhoye, M., De Groof, G., and van der Linden, A. (2013). A 3-dimensional digital atlas of the ascending sensory and the descending motor systems in the pigeon brain. Brain Struct. Funct. $218,269-81$.

Hassin, R.R., Bargh, J.A., Engell, A.D., and McCulloch, K.C. (2009). Implicit working memory. Conscious. Cogn. 18, 665-678.

Herold, C., Palomero-Gallagher, N., Güntürkün, O., and Zilles, K. (2012). Serotonin 5-HT1A receptor binding sites in the brain of the pigeon (Columba livia). Neuroscience 200, 1-12.

Kass, R.E., and Raftery A.E. (1995). Bayes Factors, J. Am. Stat. Assoc. 90:430, 773-795.

Kalenscher, T., Ohmann, T., Windmann, S., Freund, N., and Güntürkün, O. (2006). Single forebrain neurons represent interval timing and reward amount during response scheduling. Eur. J. Neurosci. 24, 2923-2931.

Kang, Z., and Spitzer, B. (2021). Concurrent visual working memory bias in sequential integration of approximate number. Sci. Rep. 11, 5348.

Karakuyu, D., Herold, C., Güntürkün, O., and Diekamp, B. (2007). Differential increase of extracellular dopamine and serotonin in the 'prefrontal cortex' and striatum of pigeons during working memory. Eur. J. Neurosci. 26, 2293-2302. 
Karten, H.J., and Hodos, W. (1967). A stereotaxic atlas of the brain of the pigeon (Columba livia). Baltimore: Johns Hopkins Press.

Kennerley, S.W., and Wallis, J.D. (2009). Reward-dependent modulation of working memory in lateral prefrontal cortex. J. Neurosci. 29, 3259-3270.

Kim, J.N., and Shadlen, M.N. (1999). Neural correlates of a decision in the dorsolateral prefrontal cortex of the macaque. Nat. Neurosci. 2, 176-185.

Koenen, C., Millar, J., and Colombo, M. (2013). How bad do you want it? Reward modulation in the avian nidopallium caudolaterale. Behav. Neurosci. 127, 544-554.

Krawczyk, D.C., Gazzaley, A., and D'Esposito, M. (2007). Reward modulation of prefrontal and visual association cortex during an incentive working memory task. Brain Res. 1141, 168-177.

Kröner, S., and Güntürkün, O. (1999). Afferent and efferent connections of the caudolateral neostriatum in the pigeon (Columba livia): a retro- and anterograde pathway tracing study. J. Comp. Neurol. 407, 228-260.

Lara, A.H., and Wallis, J.D. (2015). The Role of Prefrontal Cortex in Working Memory: A Mini Review. Front. Syst. Neurosci. 9, 173.

Lengersdorf, D., Pusch, R., Güntürkün, O., and Stüttgen, M.C. (2014). Neurons in the pigeon nidopallium caudolaterale signal the selection and execution of perceptual decisions. Eur. J. Neurosci. 40, 3316-3327.

Lilburn, S.D., Smith, P.L., and Sewell, D.K. (2019). The separable effects of feature precision and item load in visual short-term memory. J. Vis. 19, 2.

Lundqvist M., Rose J., Herman P., Brincat S.L., Buschman T.J., and Miller E.K. (2016). Gamma and Beta Bursts Underlie Working Memory. Neuron 90, 152-164.

Mante, V., Sussillo, D., Shenoy, K.V., and Newsome, W.T. (2013). Context-dependent computation by recurrent dynamics in prefrontal cortex. Nature 503, 78-84.

Moll, F.W., and Nieder, A. (2015). Cross-modal associative mnemonic signals in crow endbrain neurons, Curr. Biol. 25, 2196-2201.

Packheiser, J., Güntürkün, O., and Pusch, R. (2019). Renewal of extinguished behavior in pigeons (Columba livia) does not require memory consolidation of acquisition or extinction in a free-operant appetitive conditioning paradigm. Behav. Brain Res. 370, 111947.

Packheiser, J., Donoso, J. R., Cheng, S., Güntürkün, O., and Pusch, R. (2021). Trial-by-trial dynamics of reward prediction error-associated signals during extinction learning and renewal. Prog. Neurobiol. 197, 101901.

Panichello, M.F., and Buschman, T.J. (2021). Shared mechanisms underlie the control of working memory and attention. Nature 592, 601-605.

Panichello, M.F., DePasquale, B., Pillow, J.W., and Buschman, T.J. (2019). Error-correcting dynamics in visual working memory. Nat. Commun. 10, 3366. 
Pratte, M.S., Park, Y.E., Rademaker, R.L., and Tong, F. (2017). Accounting for stimulus-specific variation in precision reveals a discrete capacity limit in visual working memory. J. Exp. Psychol. Hum. Percept. Perform. 43, 6-17.

Rademaker, R.L., Park, Y.E., Sack, A.T., and Tong, F. (2018). Evidence of gradual loss of precision for simple features and complex objects in visual working memory. J. Exp. Psychol. Hum. Percept. Perform. 44, 925-940.

Rainer, G., Rao, S.C., and Miller, E.K. (1999). Prospective coding for objects in primate prefrontal cortex. J. Neurosci. 19, 5493-5505.

Rigotti, M., Barak, O., Warden, M.R., Wang, X.J., Daw, N.D., Miller, E.K., and Fusi S. (2013). The importance of mixed selectivity in complex cognitive tasks. Nature 497, 585-590.

Rose, J., Otto, T., and Dittrich, L. (2008). The Biopsychology-Toolbox: A free, open-source Matlabtoolbox for the control of behavioral experiments. J. Neurosci. Methods 175, 104-107.

Serre, T. (2006). Learning a dictionary of shape-components in visual cortex: comparison with neurons, humans and machines. Thesis (Ph.D.), Massachusetts Institute of Technology, Dept. of Brain and Cognitive Sciences, http://hdl.handle.net/1721.1/34270.

Serre, T., Kouh, M., Cadieu, C., Knoblich, U., Kreiman, G., and Poggio, T. (2005). A theory of object recognition: computations and circuits in the feedforward path of the ventral stream in primate visual cortex. CSAIL Technical Reports, http://hdl.handle.net/1721.1/36407.

Serre, T., Oliva, A., and Poggio, T. (2007). A feedforward architecture accounts for rapid categorization. Proc. Natl. Acad. Sci. 104, 6424-6429.

Shadlen, M.N., and Newsome, W.T. (2001). Neural basis of a perceptual decision in the parietal cortex (area LIP) of the rhesus monkey. J. Neurophysiol. 86, 1916-1936.

Starosta, S., Güntürkün, O., and Stüttgen, M.C. (2013). Stimulus-response-outcome coding in the pigeon nidopallium caudolaterale. PLoS One 8, e57407.

Starosta, S., Stüttgen, M.C., and Güntürkün, O. (2014). Recording single neurons' action potentials from freely moving pigeons across three stages of learning. J. Vis. Exp. 88.

Tang, H., Qi, X.L., Riley, M.R., and Constantinidis C. (2019). Working memory capacity is enhanced by distributed prefrontal activation and invariant temporal dynamics. Proc. Natl. Acad. Sci. 116, 70957100.

van den Berg, R., Shin, H., Chou, W.C., George, R., and Ma, W.J. (2012). Variability in encoding precision accounts for visual short-term memory limitations. Proc. Natl. Acad. Sci. 109, 8780-8785.

Veit, L., Hartmann, K., and Nieder, A. (2014). Neuronal correlates of visual working memory in the corvid endbrain. J. Neurosci. 34, 7778-86.

Wright, A.A., and Elmore, L.C. (2016). Pigeon visual short term memory directly compared to primates. Behav. Processes 123, 84-89. 


\section{Supplementary Figures}

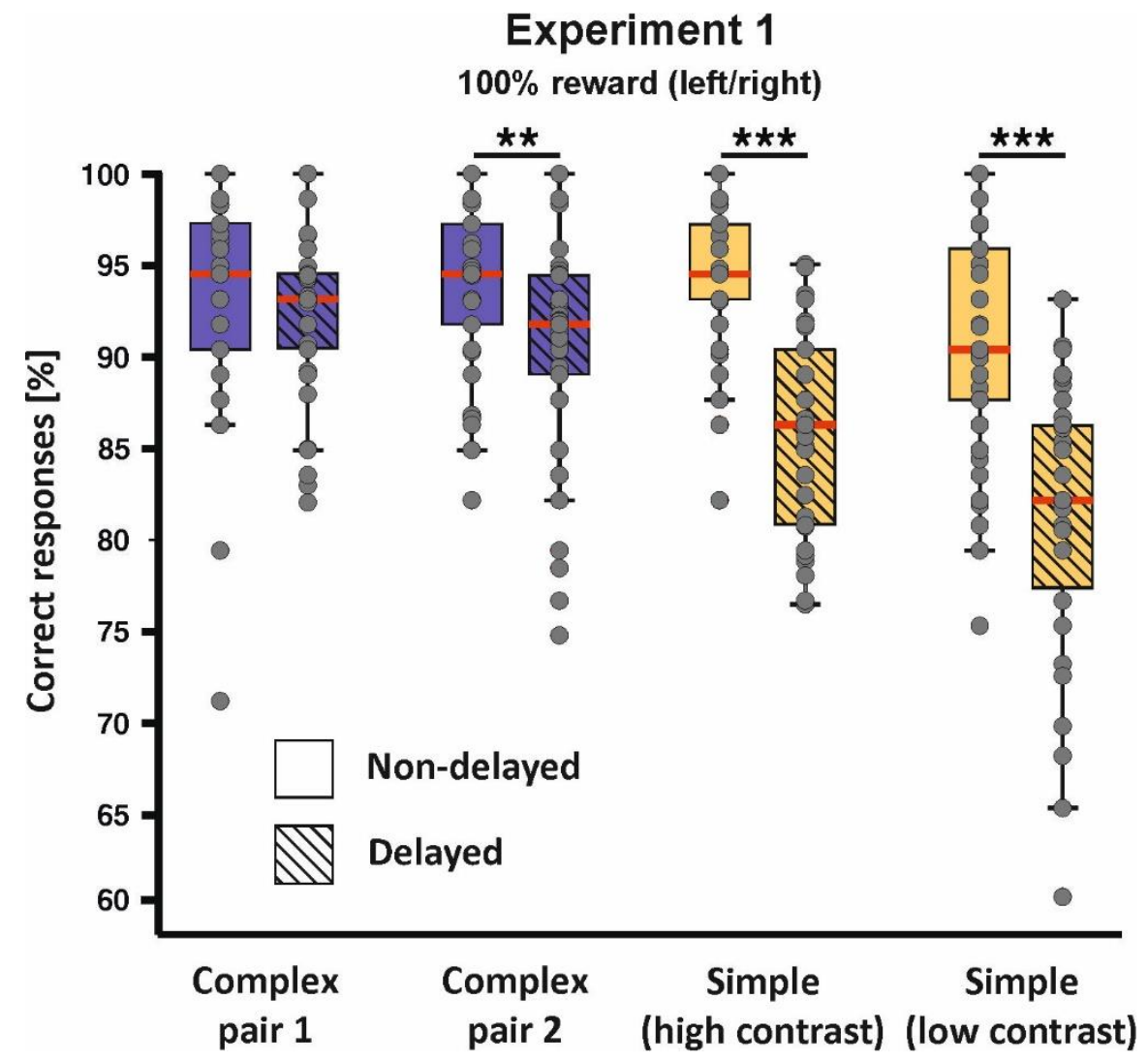

SI Figure 1. Behavioral performance of experiment 1 for all individual stimulus pairs. The introduction of the delay had differential effects on performance across stimulus pairs. Error bars represent the $95 \%$ confidence interval. 


\section{Experiment 2}

$100 \%$ reward (yellow/blue)

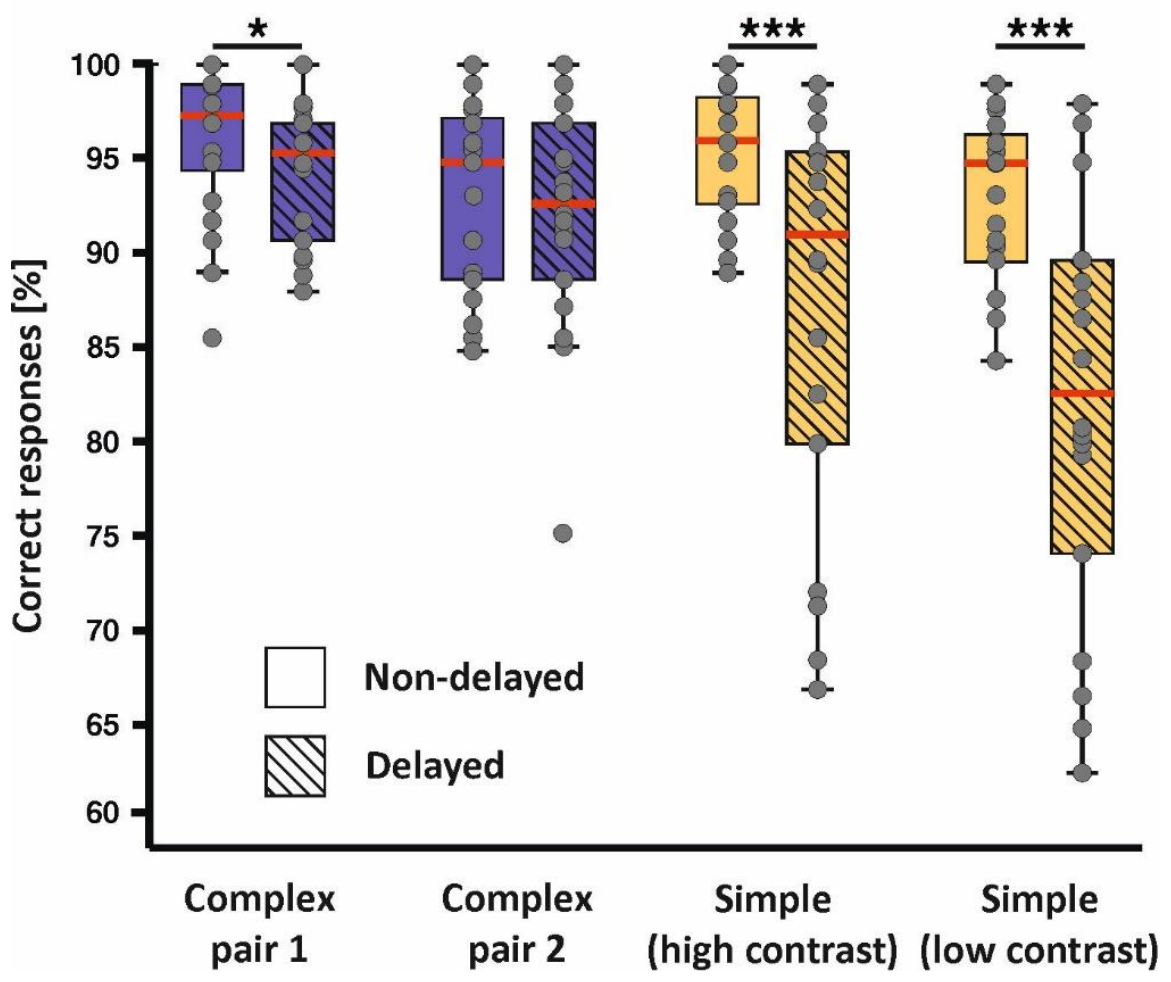

SI Figure 2. Behavioral performance of experiment $\mathbf{2}$ for all individual stimulus pairs. The introduction of the delay had differential effects on performance across stimulus pairs. Error bars represent the $95 \%$ confidence interval.

\section{Experiment 3}

Diff. reward contingencies (left/right)

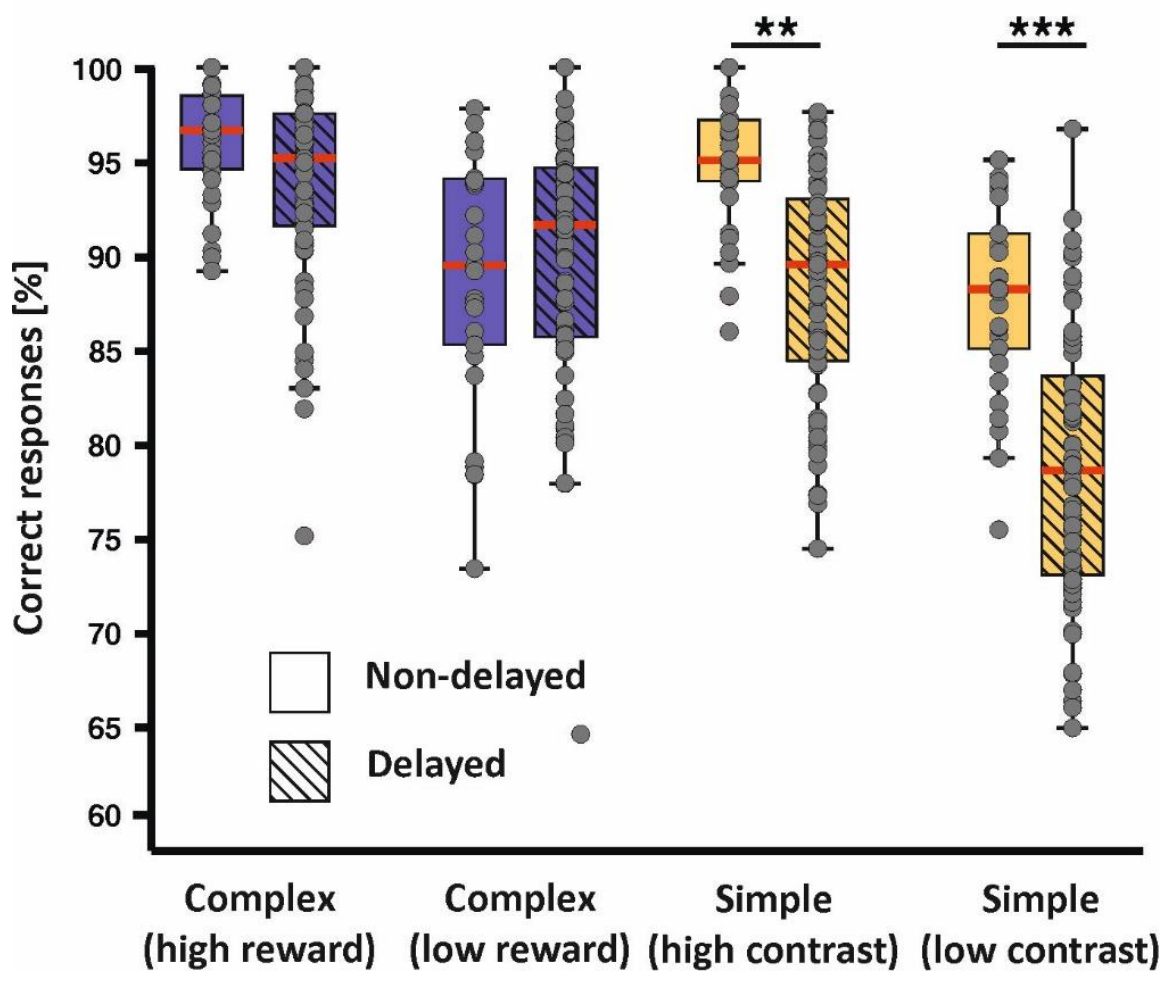

SI Figure 3. Behavioral performance of experiment $\mathbf{3}$ for all individual stimulus pairs. The introduction of the delay had differential effects on performance across stimulus pairs. Error bars represent the $95 \%$ confidence interval. 


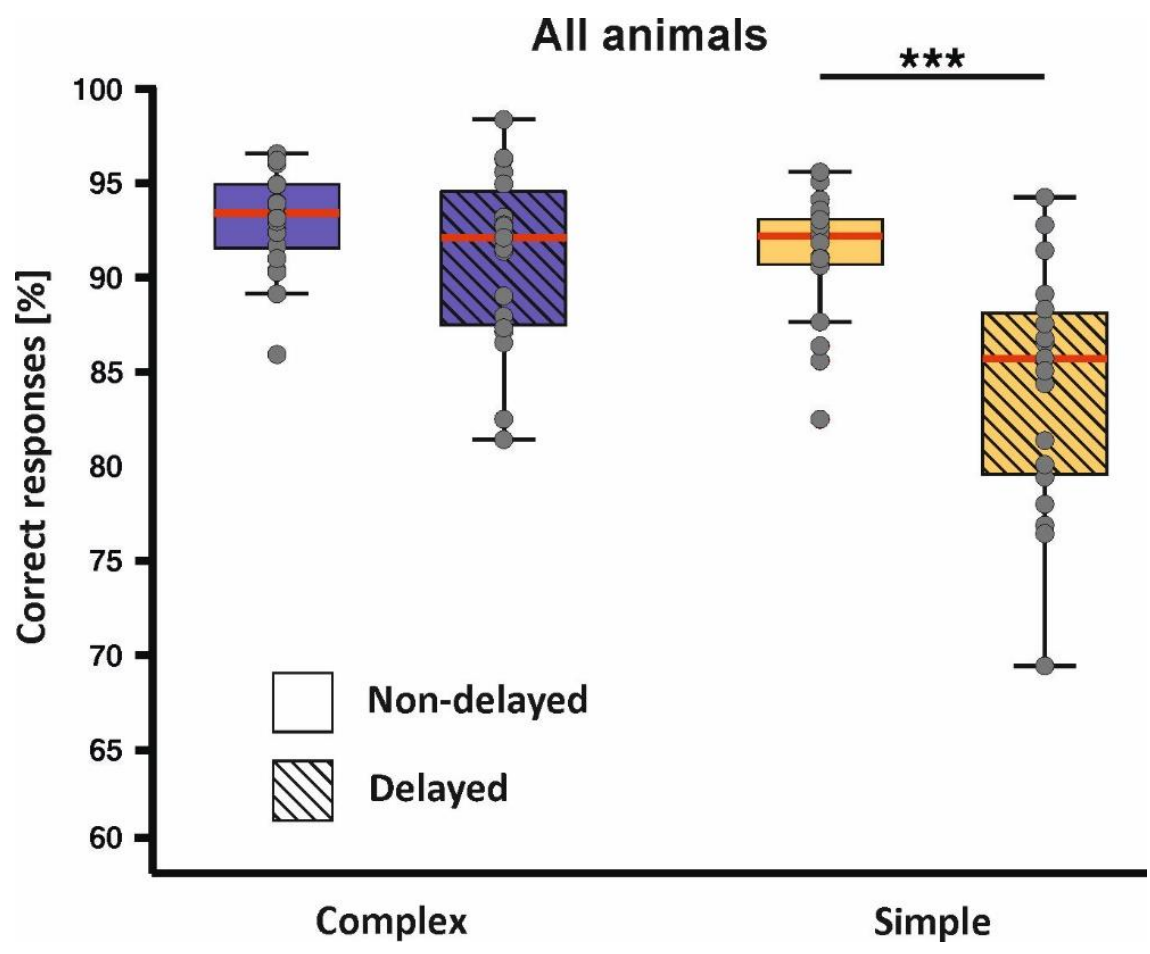

SI Figure 4. Behavioral performance from all individual animals across experiment 1-3. The introduction of the delay had differential effects on performance across stimulus classes. Error bars represent the $95 \%$ confidence interval.

A

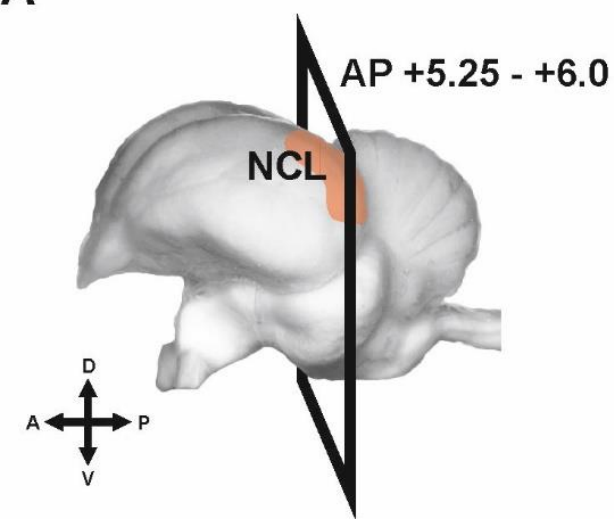

B

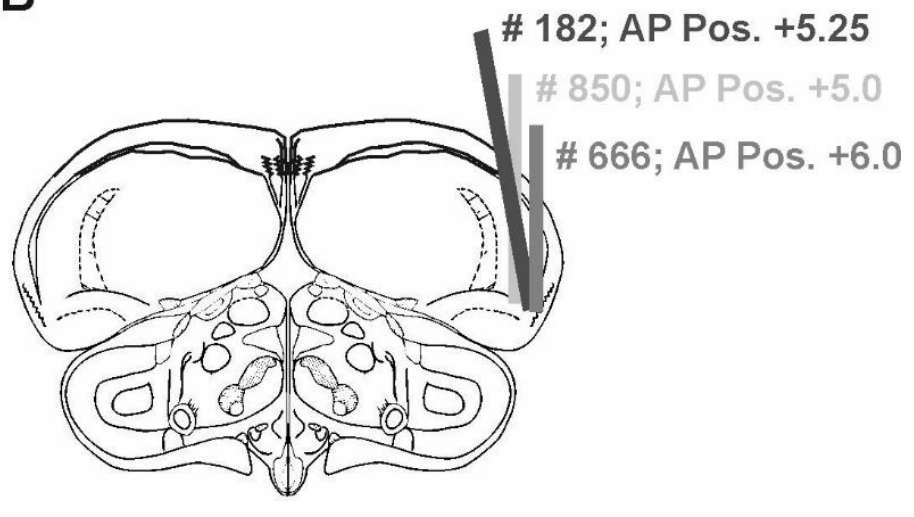

SI Figure 5. Histological analysis of electrode tracks for each individual pigeon subjected in the study. A) Sagittal view of the pigeon brain (Güntürkün et al., 2013) including the range of coronal planes of the electrode positions. B) Electrode track reconstruction for all pigeons used in this study collapsed on a coronal section of the pigeon brain. Drawings are based on the pigeon brain atlas by Karten and Hodos (1967). Gray lines indicate the location of the cannula containing the electrodes for each individual pigeon (Pigeon \# 182, \# 850 and \# 666). For all three pigeons, the electrode tracks were located within the borders of the NCL as defined by Herold et al. (2012). A: anterior; AP: anterior-posterior axis; D: dorsal; NCL: nidopallium caudolaterale; P: posterior; V: ventral. 


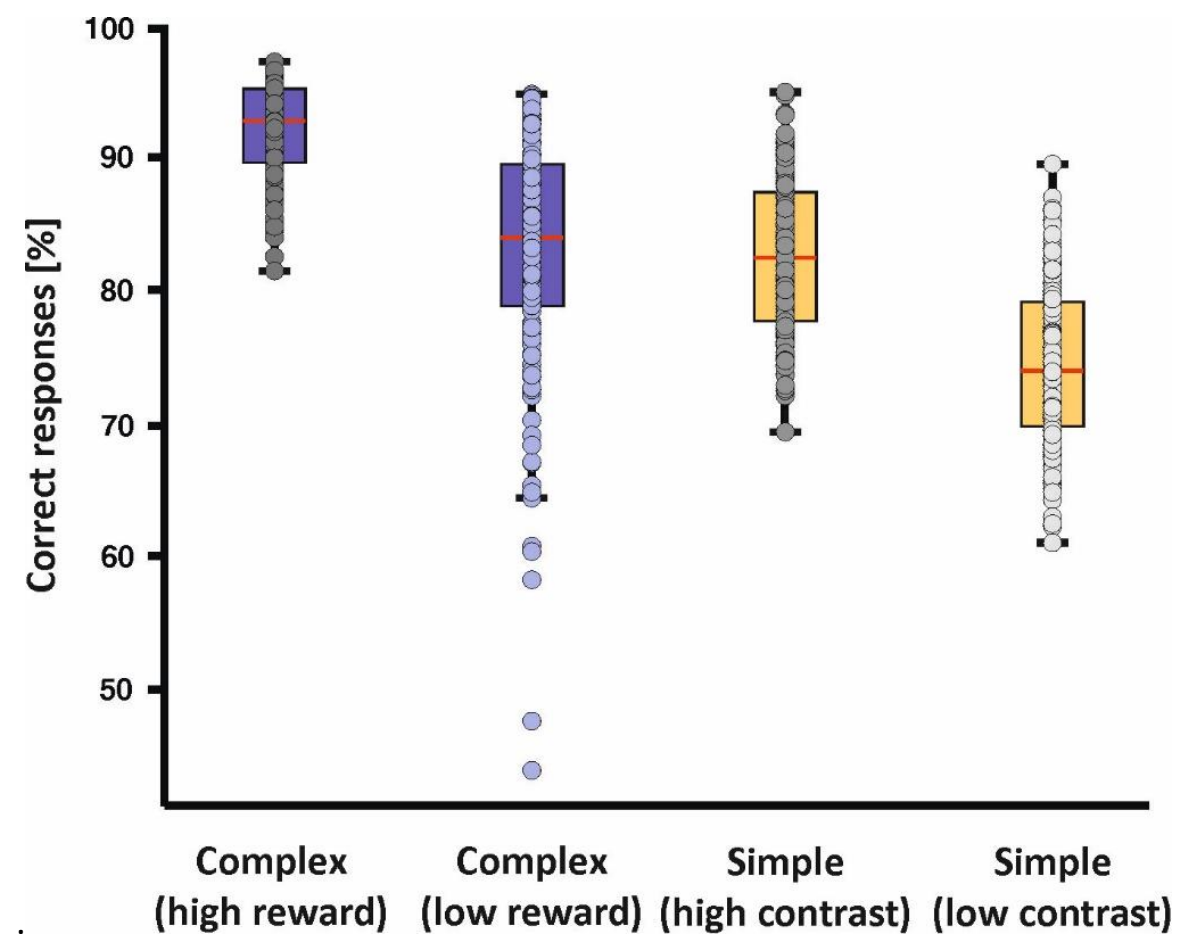

SI Figure 6. Behavioral performance during the recording sessions (only the delayed condition was run). Performance levels echoed the results of experiment 3 in the delayed condition (see Figure $2 \mathrm{C}$ ). Error bars represent the $95 \%$ confidence interval.

Correct left choices
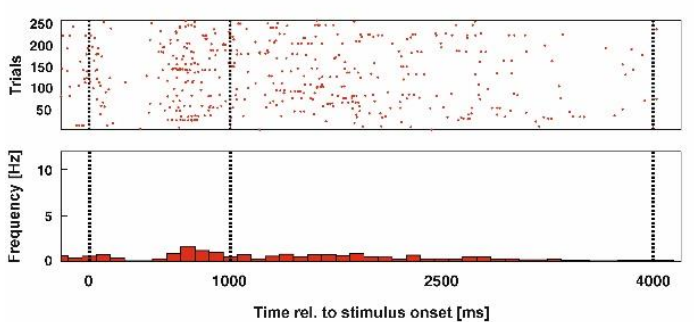

Incorrect left choices
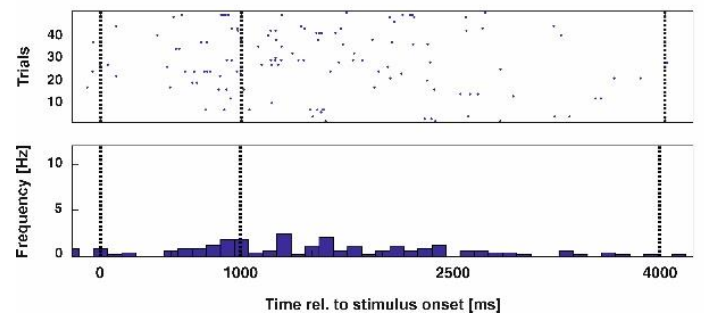

Correct right choices

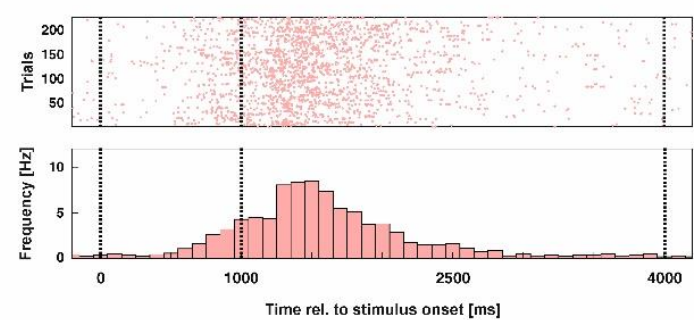

Incorrect right choices

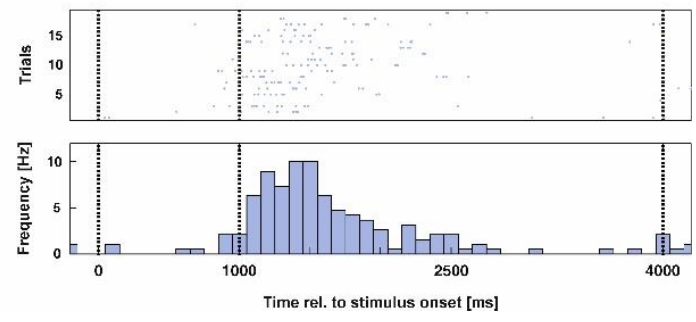

SI Figure 7. Responses of an example neuron for all left and right choices across all experimental stimuli. Top) On the left, the raster plot and PSTH for correct choices to the left response key are shown. On the right, the corresponding responses to the right response key are depicted. Bottom) Same as for the top row, but for incorrect choices. Note that the neuron was tuned to the ultimate decision irrespective of the outcome (correct vs. incorrect). 
bioRxiv preprint doi: https://doi org/10.1101/2021.09 10.459776: this version posted September 11. 2021. The copvriaht holder for this preprint (which was not certified by peer review) is the author/funder, who has granted bioRxiv a license to display the preprint in perpetuity. It is made available under aCC-BY-NC 4.0 International license.
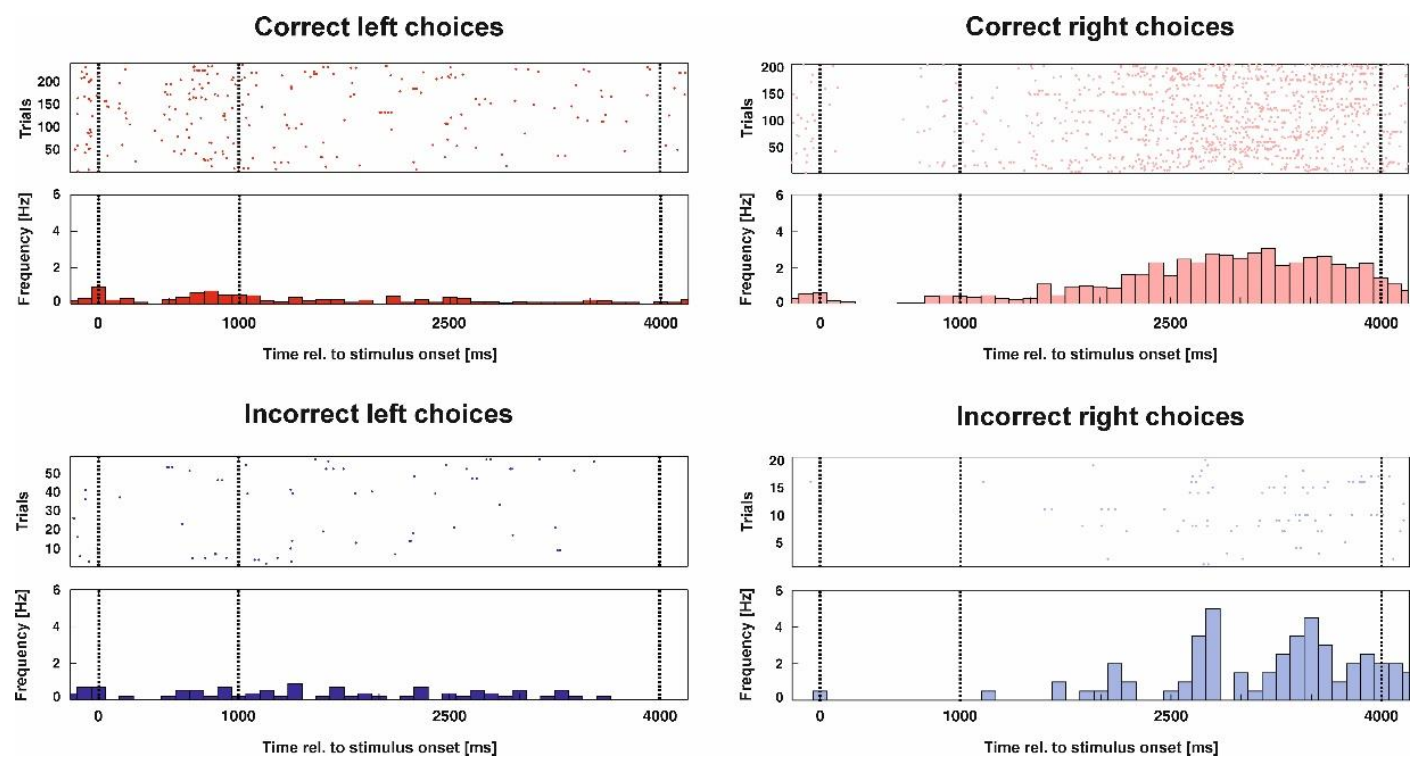

SI Figure 8. Responses of another example neuron for all left and right choices across all experimental stimuli. The structure of the figure is identical to SI Figure 7. Again, this neuron's spiking activity corresponded to the choice of the animal regardless whether it turned out to be correct or incorrect.

A

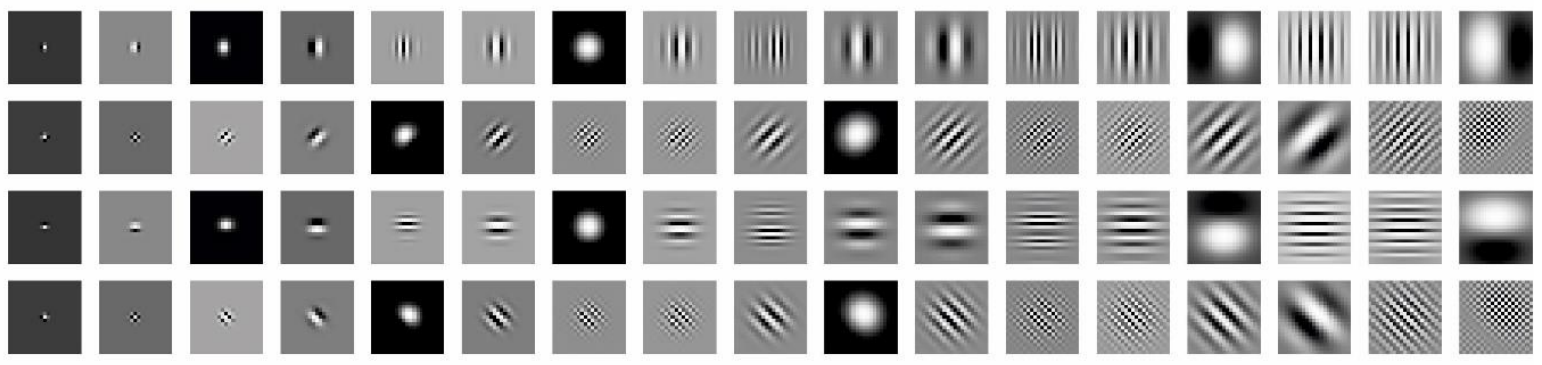

B Input stimulus

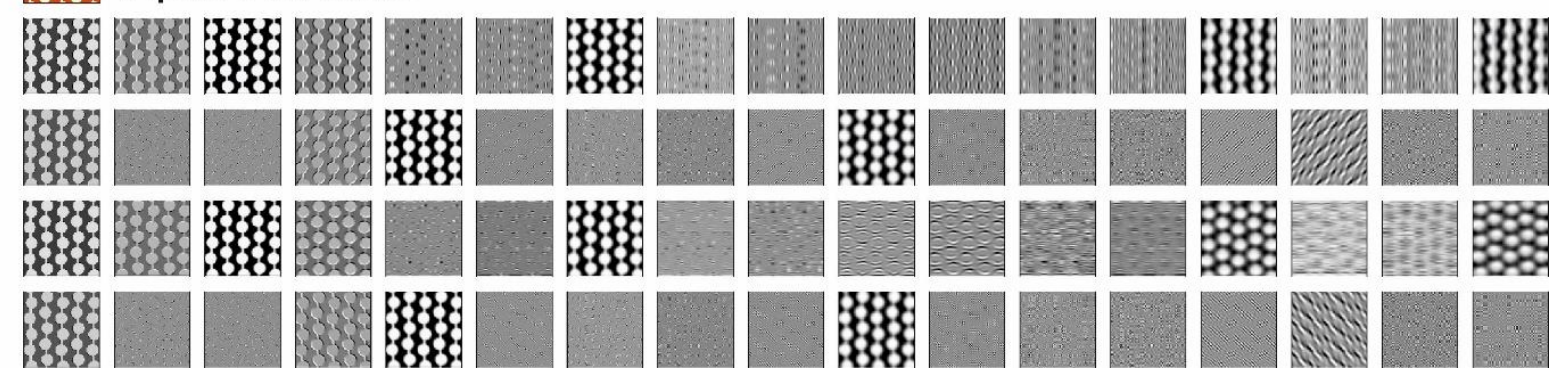

SI Figure 9. A) 68 Gabor filters used to estimate the stimulus-specific visual information of the stimulus set. B) Sample outputs after convolution of one stimulus with each Gabor filter. 
A

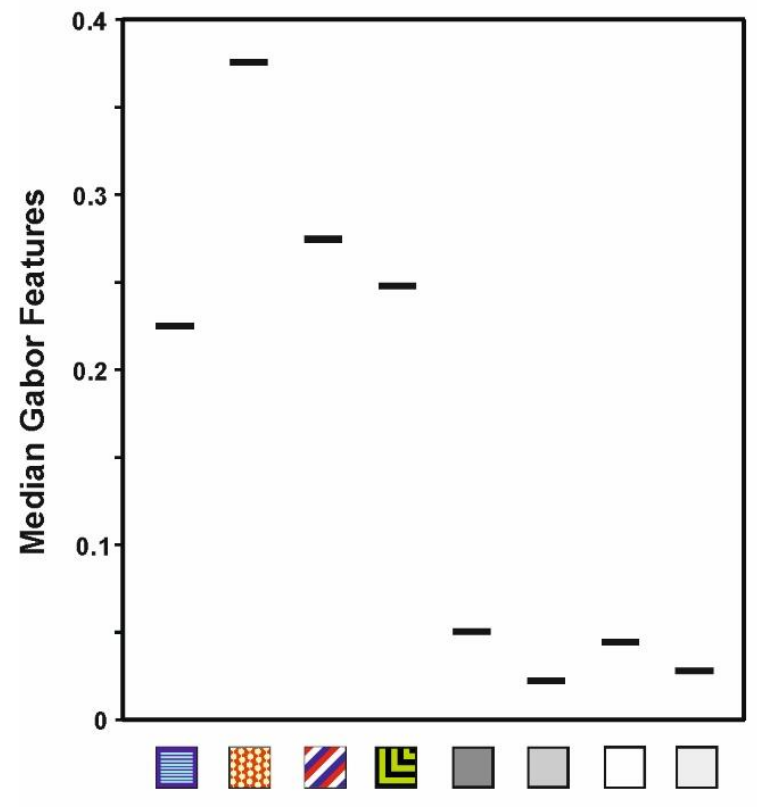

B

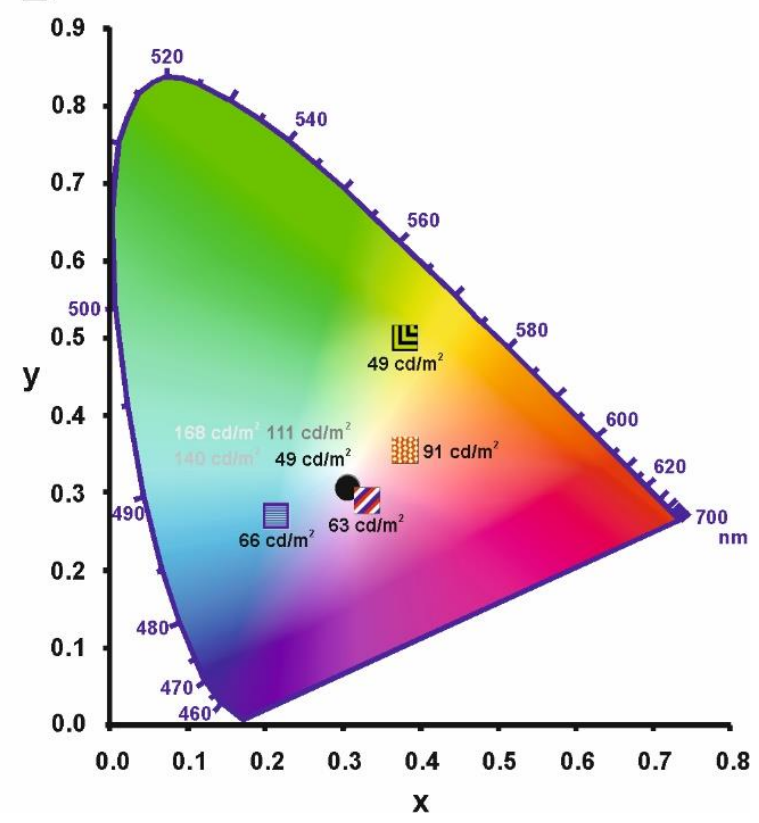

SI Figure 10. A) The median output of the 68 Gabor filters for all stimuli. The complex stimuli are characterized by spatial image features reflected by a large number of responsive Gabor filters resulting in a high median activity. The simple stimuli are void of any spatial features resulting in a marginal median Gabor filter activity. B) Representation of the stimulus set in the CIE 1931 color space chromaticity diagram. The complex stimuli are arranged within the color space and deviate from the white point of the figure. In contrast, all the simple stimuli are collapsed in the white point of the color space. Thus, besides their luminance difference, no additional color information is contained in these stimuli.

SI Table 1. Random effect residuals for the linear mixed effect models from the behavioral experiments.

\begin{tabular}{|l|c|c|c|c|}
\hline Residual & Experiment 1 & Experiment 2 & Experiment 3 & $\begin{array}{c}\text { Averaged across } \\
\text { animals }\end{array}$ \\
\hline Variance & 0.0017 & 0.0020 & 0.0023 & 0.0014 \\
\hline Standard Deviation & 0.0407 & 0.0448 & 0.0483 & 0.0375 \\
\hline
\end{tabular}

SI Table 2. Distribution of active cells per category across the sample and delay phase for the simulated data in both the complex and simple stimuli. Note that the indicated value represents an average across 200 simulations.

\begin{tabular}{|c|c|c|c|c|c|c|c|c|c|c|}
\hline \multirow{2}{*}{$\begin{array}{c}\text { Stimulus Set } \\
\text { Phase Activity } \\
\text { in Trial }\end{array}$} & \multicolumn{5}{|c|}{ Complex Stimuli } & \multicolumn{5}{|c|}{ Simple Stimuli } \\
\hline & Stimulus & Value & Integration & Choice & $\begin{array}{l}\text { Cell } \\
\text { Total }\end{array}$ & Stimulus & Value & Integration & Choice & $\begin{array}{l}\text { Cell } \\
\text { Total }\end{array}$ \\
\hline Sample Phase & $0.14(0.13 \%)$ & $0.77(0.74 \%)$ & $0.80(0.77 \%)$ & $0.84(0.81 \%)$ & $2.54(2.44 \%)$ & $0.01(0.01 \%)$ & $0.18(0.17 \%)$ & $0.17(0.16 \%)$ & $0.13(0.13 \%)$ & $0.49(0.47 \%)$ \\
\hline Delay $1^{*}$ second & $0.15(0.14 \%)$ & $0.85(0.82 \%)$ & $0.95(0.91 \%)$ & $0.83(0.8 \%)$ & $2.74(2.63 \%)$ & $0.02(0.02 \%)$ & $0.13(0.13 \%)$ & $0.14(0.13 \%)$ & $0.1(0.1 \%)$ & $0.39(0.38 \%)$ \\
\hline Delay $2^{\mathrm{nt}}$ second & $0.12(0.12 \%)$ & $0.77(0.74 \%)$ & $0.84(0.81 \%)$ & $0.76(0.73 \%)$ & $2.48(2.38 \%)$ & $0.05(0.05 \%)$ & $0.1(0.1 \%)$ & $0.09(0.09 \%)$ & $0.2(0.19 \%)$ & $0.44(0.42 \%)$ \\
\hline Delay $3^{\text {rd }}$ second & $0.12(0.12 \%)$ & $0.73(0.7 \%)$ & $0.65(0.63 \%)$ & $0.75(0.72 \%)$ & $2.23(2.14 \%)$ & $0(0 \%)$ & $0.15(0.14 \%)$ & $0.14(0.13 \%)$ & $0.09(0.08 \%)$ & $0.39(0.38 \%)$ \\
\hline
\end{tabular}

$$
\square p>0.05 \square p<0.05 \square p<0.01 \square p<0.001
$$

SI Table 3. Random effect residuals for the linear mixed effect models from the electrophysiological experiments.

\begin{tabular}{|l|c|c|c|c|c|c|}
\hline Residual & $\begin{array}{c}\text { Stimulus- } \\
\text { related activity } \\
\text { (Sample phase) }\end{array}$ & $\begin{array}{c}\text { Value-related } \\
\text { activity (Sample } \\
\text { phase) }\end{array}$ & $\begin{array}{c}\text { Value-related } \\
\text { activity (Delay } \\
\text { 1) }\end{array}$ & $\begin{array}{c}\text { Integrative } \\
\text { representations } \\
\text { (Sample phase) }\end{array}$ & $\begin{array}{c}\text { Integrative } \\
\text { representations } \\
\text { (Delay 1) }\end{array}$ & $\begin{array}{c}\text { Choice-related } \\
\text { activity (Sample } \\
\text { phase) }\end{array}$ \\
\hline Variance & 0.00032 & 0.00023 & 0.00004 & 0.00003 & 0.00003 & 0.00038 \\
\hline $\begin{array}{l}\text { Standard } \\
\text { Deviation }\end{array}$ & 0.01783 & 0.01517 & 0.00659 & 0.00551 & 0.00538 & 0.01949 \\
\hline
\end{tabular}




\section{STAR Methods}

Key Resources Table

\begin{tabular}{|c|c|c|}
\hline $\begin{array}{l}\text { REAGENT or } \\
\text { RESOURCE }\end{array}$ & SOURCE & IDENTIFIER \\
\hline $\begin{array}{l}\text { Isoflurane } \\
\text { (Forene, } \\
100 \%)\end{array}$ & $\begin{array}{l}\text { Abbot, } \\
\text { Germany }\end{array}$ & Zul.-Nr.: 2594.00.00 \\
\hline $\begin{array}{l}\text { Ketamine } \\
\text { hydrochloride } \\
\text { (Ketavet, } 100 \\
\mathrm{mg} / \mathrm{mL} \text { ) }\end{array}$ & $\begin{array}{l}\text { Zoetis, } \\
\text { Germany }\end{array}$ & Zul.-Nr.: 6187926.00 .00 \\
\hline $\begin{array}{l}\text { Xylazine } \\
\text { hydrochloride } \\
\text { (Rompun, } 20 \\
\mathrm{mg} / \mathrm{mL} \text { ) }\end{array}$ & $\begin{array}{l}\text { Bayer, } \\
\text { Germany }\end{array}$ & ATCvet-Code: QN05CM92 \\
\hline $\begin{array}{l}\text { Natrium- } \\
\text { fusidat } \\
\text { (antibiotic } \\
\text { balm; } \\
\text { Fucidine, } 20 \\
\mathrm{mg} / \mathrm{g} \text { ) }\end{array}$ & $\begin{array}{l}\text { Leo Pharma } \\
\text { A/S, Danmark }\end{array}$ & Zul.-Nr.: 6424177.00 .01 \\
\hline $\begin{array}{l}\text { Carprofen } \\
\text { (Rimadyl, } 50 \\
\mathrm{ml} / \mathrm{mL} \text { ) }\end{array}$ & $\begin{array}{l}\text { Zoetis, } \\
\text { Germany }\end{array}$ & Zul.-Nr.: 400684.00 .00 \\
\hline $\begin{array}{l}\text { Tytothricin } \\
\text { (antibiotic } \\
\text { powder; } \\
\text { Tyrosur, } 1 \\
\mathrm{mg} / \mathrm{g} \text { ) }\end{array}$ & $\begin{array}{l}\text { Engelhard } \\
\text { Arzneimittel, } \\
\text { Germany }\end{array}$ & Zul.-Nr.: 6527902.00 .01 \\
\hline mlib toolbox & $\begin{array}{l}\text { Maik Stüttgen, } \\
\text { MATLAB } \\
\text { central file } \\
\text { exchange }\end{array}$ & $\begin{array}{l}\text { https://de.mathworks.com/matlabcentral/fileexchange/37339- } \\
\text { mlib-toolbox-for-analyzing-spike-data }\end{array}$ \\
\hline
\end{tabular}




\begin{tabular}{|c|c|c|}
\hline $\begin{array}{l}\text { Spike2 } \\
\text { recording } \\
\text { software }\end{array}$ & $\begin{array}{l}\text { Cambridge } \\
\text { Electronic } \\
\text { Design, } \\
\text { Cambridge, UK }\end{array}$ & Version 7.06 \\
\hline $\begin{array}{l}\text { Alpha Lab SnR } \\
\text { recording } \\
\text { software }\end{array}$ & $\begin{array}{l}\text { Alpha Omega, } \\
\text { Nazareth Illit, } \\
\text { Israel }\end{array}$ & \\
\hline $\begin{array}{l}\text { MATLAB } \\
2018 a\end{array}$ & $\begin{array}{l}\text { The } \\
\text { Mathworks }\end{array}$ & https://de.mathworks.com \\
\hline $\begin{array}{l}\text { Teflon-coated } \\
\text { silver wire, } \varnothing= \\
75 \mu \mathrm{m}\end{array}$ & $\begin{array}{l}\text { Science } \\
\text { Products, } \\
\text { Hofheim, } \\
\text { Germany }\end{array}$ & \\
\hline $\begin{array}{l}\text { formvar- } \\
\text { insulated } \\
\text { nichrome } \\
\text { wires, } \varnothing=40 \\
\mu \mathrm{m}\end{array}$ & $\begin{array}{l}\text { California Fine } \\
\text { Wire, Grover } \\
\text { Beach, USA }\end{array}$ & \\
\hline $\begin{array}{l}\text { nichrome } \\
\text { wire, } \varnothing=75 \\
\mu \mathrm{m}\end{array}$ & $\begin{array}{l}\text { Franco Corradi, } \\
\text { Milan, Italy }\end{array}$ & SS316LWA.0762HML30; LOT 10890 \\
\hline microplugs & $\begin{array}{l}\text { Ginder } \\
\text { Scientific, } \\
\text { Nepean, CA, } \\
\text { USA }\end{array}$ & GS18PLG-220 (18-pin Plug) \\
\hline $\begin{array}{l}\text { Extracellular } \\
\text { recording } \\
\text { device }\end{array}$ & $\begin{array}{l}\text { Alpha Omega, } \\
\text { Nazarath Illit, } \\
\text { Israel }\end{array}$ & \\
\hline $\begin{array}{l}\text { The } \\
\text { Biopsychology- } \\
\text { Toolbox }\end{array}$ & $\begin{array}{l}\text { Rose, J., Otto, } \\
\text { T., and Dittrich, } \\
\text { L. (2008). }\end{array}$ & https://sourceforge.net/projects/biopsytoolbox/ \\
\hline $\begin{array}{l}\text { A2 stainless } \\
\text { steel 0-80 x 1/2 } \\
\text { inch Phillips } \\
\text { Countersunk } \\
\text { screws }\end{array}$ & $\begin{array}{l}\text { Accu, Hagg } \\
\text { Wood Stone } \\
\text { Quarry, } \\
\text { Huddersfield, } \\
\text { HD9 6PW, } \\
\text { United } \\
\text { Kingdom }\end{array}$ & SIK-0-80-1/2-A2 \\
\hline
\end{tabular}




\begin{tabular}{|l|l|l|}
\hline $\begin{array}{l}\text { Dental cement } \\
\text { Omniceram } \\
\text { évolution flow }\end{array}$ & $\begin{array}{l}\text { Omnident , D- } \\
63110 \text { Rodgau }\end{array}$ & Manufacturer number 33072 \\
\hline
\end{tabular}

\section{Lead contact and materials availability}

Further information and requests for resources and reagents should be directed to and will be fulfilled by the Lead contact, Roland Pusch (roland.pusch@rub.de).

\section{Experimental model and subject details}

Subjects were treated in accordance with the German guidelines for the care and use of animals in science and all experimental procedures were approved by a national ethics committee of the State of North Rhine-Westphalia, Germany (LANUV) and were in agreement with the European Communities Council Directive 86/609/EEC concerning the care and use of animals for experimental purposes. 25 adult homing pigeons (Columba livia) of unknown sex were used in this study. The birds used as experimental subjects were obtained from local breeders. Of these, three birds were employed in electrophysiological experiments whereas 22 animals solely took part in behavioral studies (experiment 1: 12 pigeons, experiment 2: 8 pigeons and experiment 3: 17 pigeons; animals were partially reused between experiments). Birds were accommodated individually in wire-mesh cages within a colony room ( $12 \mathrm{~h}$ light/dark cycle; beginning at 8:00 $\mathrm{h}$ ) where they had ad libitum access to water and grit. On testing days, food access was restricted and the animals were maintained between $80-90 \%$ of their free-feeding body weight.

\section{Method Details}

\section{Apparatus}

Testing was conducted in a custom-built operant chamber (33 x 34 × 34 cm; Packheiser et al., 2019).

The rear wall of the chamber featured three horizontally aligned rectangular translucent choice keys ( $4 \times 4 \mathrm{~cm}$ wide) located above a food hopper. An LCD screen was mounted against the rear wall for the presentation of stimuli at the choice key locations. Pecks to the choice-keys were immediately followed 
by auditory feedback. The chamber was illuminated by two lights at the top of the chamber with an additional feeder light affixed on top of the food hopper. The chamber was situated in a soundattenuating cubicle and all experimental sessions were conducted with a constant presentation of white noise ( $60 \mathrm{~dB})$ to prevent external noise from distracting the animals during the task. Hardware was controlled by a custom written MATLAB code (The Mathworks, Natick, MA, USA; Rose et al., 2008).

\section{Stimuli}

The stimulus set encompassed eight stimuli (Figure 1B), consisting of four shaped multicolored images (complex stimuli) and four gray stimuli of different luminance (simple stimuli). The gray stimuli were subdivided into two bright stimuli $(86.3 \%$ white and $98 \%$ white) and two dark stimuli ( $43.1 \%$ white and $54.9 \%$ white). Due to the number of luminance increments between the respective stimulus and the category boundary ( $70.6 \%$ white) they were either easy or hard to discriminate.

While the complex stimuli provide at face value more feature information compared to the simple stimuli, we also verified the images' visual information both in the spatial and color dimension. To estimate the spatial information of the stimulus classes, we used a bank of Gabor filters. These filters are used for edge detection and luminance identification in image processing and they have widely been used as a model of simple cells in the primary visual cortex (Azizi et al., 2019; Serre et al., 2005; Serre, 2006; Serre et al., 2007). The 68 distinct Gabor filters were divided into four orientations $\theta$ ( $0^{\mathrm{deg}}$, $45^{\mathrm{deg}}, 90^{\mathrm{deg}}$ and $\left.135^{\mathrm{deg}}\right)$ and 17 sizes $\mathrm{s} \in\{1, \ldots, 17\}$ using the following formula:

$$
F(x, y)=N\left[\frac{1}{N}+H(G(x, y)-1] G(x, y)\right.
$$

Here, $x$ and $y$ are the coordinates within the receptive field of the Gabor filters.

$$
N=\left(1 / \int d x \int d y G(x, y)\right)-1
$$

is the normalization factor that ensures an upper bound of 1 for Gabor convolutions.

$$
H(x)=1 \text { for } x \geq 0
$$

is the Heaviside step function. The Gabor function is defined as follows: 


$$
\exp \left(-\frac{x^{\prime 2}+\gamma^{2} y^{\prime 2}}{2 \sigma^{2}}\right) \cos \left(2 \pi \frac{x^{\prime}}{\lambda}\right)
$$

where $x^{\prime}$ and $y^{\prime}$ are defined as follows:

$$
\begin{gathered}
x^{\prime}=x \cos (\theta)+y \sin (\theta) \\
y^{\prime}=-x \sin (\theta)+y \cos (\theta) .
\end{gathered}
$$

The width of the Gabor filter based on the size of the filter,

$$
\sigma=0.0036 s^{2}+0.35 s+0.18
$$

And the frequency of the width,

$$
\lambda=\frac{\sigma}{0.8} .
$$

The Gabor filters are shown in SI Figure 9. We calculated the convolution of the filters with each image used in the study. The average absolute values of the pixels in the resulting convoluted images were then arranged into a vector representing the image. We then extracted the median feature density of each stimulus (SI Figure 10A).

To estimate the color information of the stimulus classes, we measured the luminance and chromaticity using a Konica Minolta Chroma Meter (CS-150) and averaged the result over 10 repeated measurements (SI Figure 10B).

\section{Behavioral paradigm}

Subjects were trained in a paired association task that was divided into three distinct experimental conditions (Figure 1): in all experiments, a placeholder initialization stimulus appeared on the center key for up to three seconds after an intertrial interval (ITI) of six seconds. A peck to the initialization stimulus resulted in the presentation of one of the eight sample stimuli for a fixed duration of one second on the center key. Following stimulus presentation, the trial continued either with or without a delay period. In the task without a delay, the animals could immediately proceed to the next experimental phase when the confirmation key was pecked. In the delayed condition, a working 
bioRxiv preprint doi: https:/doi org/10.1101/2021.0910.459776; this version posted September 11,2021 . The copyright holder for this preprint (which was not certified by peer review) is the author/funder, who has granted bioRxiv a license to display the preprint in perpetuity. It is made available under aCC-BY-NC 4.0 International license.

memory interval of three seconds followed the stimulus during which the placeholder stimulus was presented. The different conditions were tested blockwise so that the sessions were either "nondelayed" or "delayed" sessions. After the three second working memory interval, a peck on the placeholder stimulus cleared the center key and activated the choice keys left and right to the placeholder. Depending on the stimulus identity, a choice A or B had to be executed within a time interval of three seconds. The association of the stimuli with choice A and B was counterbalanced across all experiments. Depending on the experiment, this choice was either a spatially fixed choice to the left or to the right (experiment 1, 3 and the electrophysiological experiment) or a blue or yellow target color that randomly appeared on the left or right response key (experiment 2, see Figure 1B). In case of a correct choice, the animals were rewarded by having access to food for two seconds. The ambient light in the operant chamber was turned off for two seconds when a wrong decision was made.

In the behavioral experiments, effects of stimulus-specific spatial and color information on working memory performance were systematically investigated (all experimental procedures are given in Figure 1B). In experiment 1, we were interested in differences in task performance due to stimulusspecific visual information under uniform reward contingencies with $100 \%$ reward probability for all stimuli using either a simple paired association task (non-delayed condition) or an additional working memory component (delayed condition). Experiment 2 replicated the experimental procedure of experiment 1 , but additionally dissociated the upcoming choice from a specific spatial location to account for potential spatial memory effects. In experiment 3, we aimed to control for the potential effects of altered reward contingencies on working memory performance. In this experiment, two complex stimuli with opposing choice contingencies received a reward in $30 \%$ of all correct choices. The other two complex stimuli were associated with a reward probability of $90 \%$. Simple stimuli received an intermediate amount of reward, i.e. a $50 \%$ reward probability in this experiment. 


\section{Behavioral data analysis}

To enter further behavioral analysis, all sessions had to meet the following criteria: At least $70 \%$ correct choices had to be reached to ensure that choices reflected learned behavior. Behavioral performance of the animals was analyzed using linear mixed model with "delay" (yes/no as levels) and "stimulus" (levels: complex stimuli, simple stimuli) as fixed effects and the individual animal as a random effect for every condition. This analysis was computed to identify how the task performance changes over time in relation to the stimulus-specific information. All post hoc corrections were calculated using Bonferroni's method. We also quantified effect sizes for post hoc comparisons (Cohen's $d$ ) and estimated the evidence in favor for the alternative hypothesis based on the conventions given in Cohen (1988). Behavioral data originating from electrophysiological recording sessions were analyzed separately and behavioral results obtained in the electrophysiological experiments were independent of all other behavioral tests.

\section{Surgery}

After reaching stable behavioral performance for both stimulus classes, microdrives for electrophysiological recordings were implanted. Pigeons were initially anesthetized with an injection of Ketamine (Ketavet, $100 \mathrm{mg} / \mathrm{mL}$; Zoetis, Germany) and Xylazine (Rompun, $20 \mathrm{mg} / \mathrm{mL}$; Bayer, Germany; ratio 7:3; 0,075 $\mathrm{ml} / 100 \mathrm{~g}$ body weight). Feathers overlying the head were removed and subjects were fixated in a stereotactic apparatus. Anesthesia was maintained by constant exposure to Isoflurane (Forene, $100 \%$ Isoflurane; Abbot, Germany). Once reflexes were tested negatively for pain perception, the scalp was cut and retracted. Stainless steel screws were placed in the skull to serve as anchors for dental acrylic. Small craniotomies were drilled above the NCL (coordinates AP +5.5 and $\mathrm{ML} \pm 7.5$ (Karten and Hodos, 1967)). After transection of the dura mater, electrode tips were lowered directly below the brain surface. Custom-built implants (Bilkey and Muir, 1999; Bilkey et al., 2003) were anchored with dental acrylic and another hole was drilled in which a ground electrode was inserted (Teflon-coated silver wire, $\varnothing=75 \mu \mathrm{m}$, Science Products, Hofheim, Germany). The incised skin was covered with antibiotic balm (Fucidine, $20 \mathrm{mg} / \mathrm{g}$ Natriumfusidat; Leo Pharma A/S, Danmark) and sutured. Following surgery, all animals received analgesic injections with Carprofen (Rimadyl, $50 \mathrm{ml} / \mathrm{mL}$ 
bioRxiv preprint doi: https://doi.org/10.1101/2021.09.10.459776; this version posted September 11, 2021. The copyright holder for this preprint (which was not certified by peer review) is the author/funder, who has granted bioRxiv a license to display the preprint in perpetuity. It is made available under aCC-BY-NC 4.0 International license.

Carprofen; Zoetis, Germany) and antibiotic powder treatment (Tyrosur, 1 mg/g Tytothricin; Engelhard Arzneimittel, Germany) for three days and were allowed to recover for at least ten days.

\section{Electrophysiology}

Recordings of neural signals and their analysis followed the procedures described in detail in Starosta et al. (2014). In brief, neural signals were recorded by fifteen $40 \mu \mathrm{m}$ formvar-insulated nichrome wires (impedances < $0.01 \mathrm{M} \Omega$; California Fine Wire, Grover Beach, USA). One $75 \mu \mathrm{m}$ nichrome wire (Franco Corradi, Milan, Italy) was used as a reference. All electrodes were connected using microplugs (Ginder Scientific, Nepean, CA, USA). The electrodes were advanced by turning the drive screw at least a quarter revolution ( $60 \mu \mathrm{m}) 15$ minutes before each recording session. Signals were amplified (400x), band-pass-filtered ( 0.5 to $5 \mathrm{kHz}$ ) and, digitized using an analog-to-digital converter (sampled at a frequency of $22 \mathrm{kHz}$; Alpha Omega, Nazareth Illit, Israel). Data were recorded using Alpha Lab SnR recording software (Alpha Omega, Nazareth Illit, Israel) and analyzed using Spike2 (Version 7.06; Cambridge Electronic Design, Cambridge, UK). Suspected neural spikes were identified through amplitude thresholds, sorted manually using principal component analysis (PCA) and cluster correlations (Spike2, Version 7.06; Cambridge Electronic Design, Cambridge, UK). The classification as single units was performed using a custom-written MATLAB code and required a clearly dissociated distribution in the PCA space, absence of brief interspike intervals $(<4 \mathrm{~ms})$ and, symmetrical distributions of spikes with minimal and maximal peak amplitudes (MLIB toolbox, Maik Stüttgen, MATLAB central file exchange \# 37339). Signal-to-noise-ratios (SNR) of at least 2.0 were mandatory (SNR was computed by dividing the peak-to-peak amplitude against the noise band distribution ranging from the $2.5^{\text {th }}$ and $97.5^{\text {th }}$ percentile of the noise band). Additionally, we manually controlled the channels for spike events during pecking movements and computed the number of spikes occurring in an interval of \pm 20 ms surrounding a key peck in a peri-peck time histogram (PPTH). Units that specifically fired during the temporal interval surrounding key pecks were excluded from further analysis to avoid potential pecking-artifacts (Starosta et al., 2013). 


\section{Neural data analysis}

Raw spike counts were filtered with an exponentially modified Gaussian kernel with 100 ms as standard deviation and a 100 ms time constant of the exponential function for the computation of spike density functions (SDF). The onset of the sample stimulus served as the temporal origin $(t=0)$ for the sample phase. Relevant pre- and post-timings were calculated individually depending on the duration and nature of the phase. For the overall data analysis, only neural activity during correct trials was analyzed. We also computed activity in error trials however to identify whether neural activity was behaviorally relevant.

\section{Task related activity - Cell classification}

To investigate task-related activity, we computed two-way ANOVAs with factors "value" (two levels, "high" and "low"; see below) and "choice" (left or right) separately for the complex and simple stimuli. The stimulus classes were analyzed separately as we identified major performance differences between them in the preceding behavioral experiments. Value was defined in terms of reward probability in the case of the complex stimuli, i.e. high vs low reward probability. For the simple stimuli, value was defined through the distinct discrimination difficulty at a constant reward probability. Low contrast stimuli led to lower behavioral performances and consequently yielded lower net outcomes, i.e. less reward events across the session compared to the high contrast stimuli.

The two-way ANOVA was applied as a sliding window analysis with $250 \mathrm{~ms}$ window and $100 \mathrm{~ms}$ step sizes from $500 \mathrm{~ms}$ before the sample onset until the end of the delay phase. The outcome phase was not further investigated as reward modulation has been described in the NCL in many different aspects before, such as reward prediction error (Lengersdorf et al., 2014; Packheiser et al., 2021; Starosta et al., 2014), reward amount, and subjective reward value (Kalenscher et al., 2006; Koenen et al., 2013). We quantified the information carried by neurons using a measure of effect size $\left(\eta_{p}{ }^{2}\right.$, reflecting the percent of explained variance), derived from our ANOVA using the following formula:

$$
\eta_{\mathrm{p}}{ }^{2}=\frac{S S_{E f f e c t}}{S S_{E f f e c t}+S S_{\text {Error }}}
$$


Here, $\mathrm{SS}_{\text {Effect }}$ reflects the sum of squares of the observed effect and $\mathrm{SS}_{\text {Error }}$ reflects the sum of squared differences between each observation and the group mean. In general, effect sizes are regarded as "small" for values of $0.02<\eta_{p}{ }^{2}<0.1$, moderate for values of $0.1<\eta_{p}{ }^{2}<0.2$ and "large" for values of $\eta_{p}^{2}$ $>0.2$ (see Cohen, 1988). To solely account for relevant modulation and rule out accidental fluctuations in spike rates, we chose a threshold of $\eta_{p}{ }^{2} \geq 0.03$ that occurred at least in two consecutive analysis windows. This can be regarded as a conservative measure as every above-threshold time window offered highly significant results in the ANOVA $(p<.01)$.

Using the effect sizes of the ANOVA, we categorized NCL neurons into non-mutually exclusive categories:

1. If value, choice and interaction effects occurred at the same time, a single neuron represented one single stimulus in particular at a certain point in time during the task. If a neuron displayed this effect size pattern, it was categorized as stimulus-related activity. This classification of stimulus-related activity was previously used in Rainer et al. (1999).

2. If a neuron exhibited above threshold effects for the factor value, it was categorized as valuerelated activity.

3. If a neuron exhibited above threshold effects for the interaction between value and response, it was categorized as an integrative representation.

4. If a neuron exhibited above threshold effects for the factor choice, it was categorized as choice-related activity.

To allow for a comparison between the sample and delay phase and to provide more insight into the temporal dynamics of activity changes, we analyzed $1 \mathrm{~s}$ epochs during the trials comprising the sample phase as well as the first, second and third second of the delay.

\section{Chance-based quantity of active cells per category}

After each neuron's activity pattern had been classified for each experimental phase, we aimed to identify whether the occurrence of a particular pattern was significantly different from chance. To 
bioRxiv preprint doi: https://doi org/10.1101/2021.0910.459776; this version posted September 11,2021 . The copyright holder for this preprint (which was not certified by peer review) is the author/funder, who has granted bioRxiv a license to display the preprint in perpetuity. It is made available under aCC-BY-NC 4.0 International license.

quantify the chance-level estimation of the category analysis, we conducted 200 permutations of the data in which we randomly assigned the groups to the observed firing rates during the experiment. Here, raw firing rates were no longer associated with for example left and right choices as they occurred within the experiments or with high and low reward outcomes, as group assignments in the ANOVA were randomly shuffled. Thus, only stochastic above threshold effects would be detected in this permutation test. As before, we then categorized the results from each permutation accordingly into the four activity categories (stimulus, value, integrative and/or choice) during each iteration. Since the permutation data barely ever demonstrated effects above the conservative threshold of $\eta_{p}^{2} \geq 0.03$, we were more liberal in the classification into the stimulus category which usually required the factors value, response and their interaction to display above threshold effects. In the permutation test, only two of the three effects of the ANOVA had to exhibit above threshold effects to be categorized into stimulus-related activity. We then tested the frequency of stimulus, value, integrative and choice cells in the data for significance by comparing the occurrence of cells in each category in the recorded and the shuffled data using Fisher's exact test. Since the averaged data thus provided a fractional number, we rounded these numbers up to the nearest positive integer to provide a valid input for Fisher's exact test.

\section{Class comparison using a linear mixed model}

In a further step, we also analyzed qualitative differences between the complex and simple stimuli on the physiological level. To this end, we computed the mean effect size $\left(\eta_{p}{ }^{2}\right)$ for each category per individual neuron during the sample phase and each second of the delay in the trial. The mean effect was calculated through dividing the observed effect of each neuron by the number of recorded neurons (104). This average was always calculated over 10 bins as each individual analysis phase consisted of 10 individual bins per 100 ms duration. The mean effect size observed during the presentation of complex and simple stimuli was then compared for the sample phase and each second of the delay phase using a linear mixed model using the stimulus class as fixed effect and the individual animal and recording session as random effects. We also quantified effect sizes for post hoc 
comparisons (Cohen's $d$ ) and estimated the evidence in favor for the alternative hypothesis based on the conventions given in Cohen (1988).

\section{Neural activation schemes}

Finally, we aimed to analyze neuronal multiplexing in the NCL population as the previous analyses were not informative whether activity patterns dynamically changed in single neurons across the trial. To this end, we generated four post hoc categories reflecting the most apparent activity patterns that emerged within the population. In contrast to the previous categorization, categories were mutually exclusive in this analysis.

1. Neurons were categorized as "early choice" if they exhibited choice-related activity patterns already during the sample phase and demonstrated neither stimulus, value, nor integrative effects.

2. Neurons were categorized as "late choice" if they exhibited choice-related activity patterns only after delay onset and demonstrated neither stimulus, value, nor integrative effects.

3. Neurons were categorized as "stimulus - no choice" if they exhibited stimulus, value, or integrative effects, but no choice-related activity patterns during the sample and delay phase.

4. Neurons were categorized as "stimulus - choice" if they exhibited stimulus, value, or integrative effects and then dynamically switched to choice-related activity patterns later during the trial.

We then compared the number of neurons that were categorized in the four categories for the complex and simple stimuli using Pearson's $\chi^{2}$ test. We also tested if observed choice-related effects were subject to change over time during the delay phase (trace decay). To this end, we calculated the average effect for all neurons involved in choice coding (early, late and stimulus-choice neurons) for the complex and simple stimuli in the first and the last second of the delay phase. This averaged effect was then compared using a paired t-test. 